Nova Southeastern University

Florida

NSUWorks

NOVA SOUTHEASTERN

UNIVERSITY

NSUWorks

$11-2010$

\title{
Genetic Introgression and the Survival of Florida Panther Kittens
}

\author{
Jeffrey A. Hostetler \\ University of Florida - Gainesville \\ David P. Onorato \\ Florida Fish and Wildlife Conservation Commission \\ James D. Nichols \\ US Geological Survey \\ Warren E. Johnson \\ National Cancer Institute at Frederick \\ Melody E. Roelke \\ National Cancer Institute at Frederick
}

See next page for additional authors

Follow this and additional works at: https://nsuworks.nova.edu/cnso_bio_facarticles

Part of the Biodiversity Commons, Genetics and Genomics Commons, and the Zoology Commons

\section{NSUWorks Citation}

Hostetler, Jeffrey A.; David P. Onorato; James D. Nichols; Warren E. Johnson; Melody E. Roelke; Stephen J. O'Brien; Deborah Jansen; and Madan K. Oli. 2010. "Genetic Introgression and the Survival of Florida Panther Kittens." Biological Conservation 143, (11): 2789-2796. https://nsuworks.nova.edu/ cnso_bio_facarticles/438

This Article is brought to you for free and open access by the Department of Biological Sciences at NSUWorks. It has been accepted for inclusion in Biology Faculty Articles by an authorized administrator of NSUWorks. For more information, please contact nsuworks@nova.edu. 


\section{Authors}

Jeffrey A. Hostetler, David P. Onorato, James D. Nichols, Warren E. Johnson, Melody E. Roelke, Stephen J. O'Brien, Deborah Jansen, and Madan K. Oli 


\title{
Genetic Introgression and the Survival of Florida Panther Kittens
}

\author{
Jeffrey A. Hostetlera, ${ }^{*}$, David P. Onoratob, James D. Nichols ${ }^{c}$, Warren E. Johnson ${ }^{d}$, Melody \\ E. Roelke ${ }^{d, e}$, Stephen J. O'Briend, Deborah Jansen ${ }^{\dagger}$, and Madan K. Olia \\ aDepartment of Wildlife Ecology and Conservation, 110 Newins-Ziegler Hall, University of Florida, \\ Gainesville, FL 32611-0430 \\ bFlorida Fish and Wildlife Conservation Commission, 298 Sabal Palm Road, Naples, FL 34114 \\ 'Patuxent Wildlife Research Center, U.S. Geological Survey, 12100 Beech Forest Road, Laurel, \\ MD 20708-4017 \\ dLaboratory of Genomic Diversity, National Cancer Institute, Frederick MD 21702-1201 \\ eSAIC-Frederick, National Cancer Institute, Frederick MD 21702-1201, USA \\ 'Big Cypress National Preserve, 33100 Tamiami Trail East, Ochopee, FL 34141, USA
}

\begin{abstract}
Estimates of survival for the young of a species are critical for population models. These models can often be improved by determining the effects of management actions and population abundance on this demographic parameter. We used multiple sources of data collected during 1982-2008 and a live recapture-dead recovery modeling framework to estimate and model survival of Florida panther (Puma concolor coryi) kittens (age 0 - 1 year). Overall, annual survival of Florida panther kittens was $0.323 \pm 0.071$ (SE), which was lower than estimates used in previous population models. In 1995 , female pumas from Texas (P. c. stanleyana) were released into occupied panther range as part of an intentional introgression program to restore genetic variability. We found that kitten survival generally increased with degree of admixture: $F_{1}$ admixed and backcrossed to Texas kittens survived better than canonical Florida panther and backcrossed to canonical kittens. Average heterozygosity positively influenced kitten and older panther survival, whereas index of panther abundance negatively influenced kitten survival. Our results provide strong evidence for the positive populationlevel impact of genetic introgression on Florida panthers. Our approach to integrate data from multiple sources was effective at improving robustness as well as precision of estimates of Florida panther kitten survival, and can be useful in estimating vital rates for other elusive species with sparse data.
\end{abstract}

\section{Keywords}

Burnham model; carnivore; Florida panther; juvenile; model averaging; survival

\footnotetext{
(C) 2010 Elsevier Ltd. All rights reserved.

*Corresponding author, hostetle@ufl.edu, telephone +1-352-846-0648, fax +1-352-392-6984.
}

Publisher's Disclaimer: This is a PDF file of an unedited manuscript that has been accepted for publication. As a service to our customers we are providing this early version of the manuscript. The manuscript will undergo copyediting, typesetting, and review of the resulting proof before it is published in its final citable form. Please note that during the production process errors may be discovered which could affect the content, and all legal disclaimers that apply to the journal pertain. 


\section{Introduction}

Rigorous estimates of survival rates and understanding factors influencing those rates are critical for discerning proximate and ultimate causes of dynamics, regulation, and persistence of populations (Newton 2004; Ozgul et al. 2006) and for devising and implementing management interventions for species conservation (Davis et al. 2007). Population dynamics of many vertebrate species are strongly influenced by changes in survival rates (Heppell et al. 2000; Oli and Dobson 2003; Stahl and Oli 2006). Estimates of survival also are necessary for the parameterization of population models, which are essential tools in conservation biology for evaluating population performance, diagnosing the causes of low numbers or population declines, developing solutions to those problems, and determining research priorities (Caswell 2001; Caughley and Gunn 1996; Fujiwara and Caswell 2001). These population models can often be improved by including the estimated effects of factors such as population density or genetic diversity on survival.

The Florida panther (Puma concolor coryi) is a subspecies of puma that once ranged throughout the southeast United States. Florida panthers give birth to 1-4 kittens, which remain in the den for approximately 7-8 weeks (Maehr et al. 1990). Average age of independence is just over 1 year (mean $=397$ days, $\mathrm{SD}=75$ days, $n=35$; FWC \& NPS, unpublished data). The Florida panther is now restricted to $<5 \%$ of its historic range in south Florida (Maehr et al. 2002), where it occurs in a single population with ca. 100 sub-adults and adults (McBride et al. 2008). It has been federally listed as endangered since 1967. Small population size, isolation, loss and fragmentation of habitat, road-related mortalities, and other anthropogenic influences continue to threaten the long-term persistence of Florida panthers (Kautz et al. 2006).

Small populations are expected to suffer from inbreeding depression (Frankham et al. 2002); earlier studies of Florida panthers found evidence of inbreeding and recommended genetic introgression via the introduction of a subspecies of puma whose range historically abutted with the range of the Florida panther (Barone et al. 1994; Roelke et al. 1993). Based on this recommendation, 8 female Texas pumas (P. c. stanleyana) were released into the Florida panther population in 1995. Although the panther population has experienced an almost fourfold increase since 1995 (McBride et al. 2008), the success of the introgression continues to be a topic of debate (Maehr et al. 2006; Onorato et al. 2010; Pimm et al. 2006). There have also been non-management releases of captive pumas into south Florida; some of these (between 1957 and 1967) resulted in a genetic population with partial Central American ancestry in the Everglades (O'Brien et al. 1990).

In 2003, the U.S. Fish and Wildlife Service (USFWS) and the Florida Fish and Wildlife Conservation Commission (FWC) convened the Scientific Review Team (SRT) to review the status of Florida panther science, and to make research and management recommendations. The SRT thoroughly reviewed existing literature on demography and population ecology of the panther, and found that rigorous estimates of age- or stage-specific survival rates and causespecific mortality rates were not available. Furthermore, SRT found that previously reported estimates of the survival rate of Florida panther kittens (Maehr and Caddick 1995) and those used in population viability analyses (Maehr et al. 2002) were not based on reliable inference methods and raised doubt on predictions regarding the persistence of the panther population (Beier et al. 2003; Beier et al. 2006; Gross 2005). The SRT recommended reanalysis of existing data to rigorously estimate age-specific survival rates and test hypotheses regarding factors influencing survival rates (Beier et al. 2003).

In accordance with SRT recommendations (Beier et al. 2003), our goals were to provide rigorous estimates of survival of Florida panther kittens (defined here as age $0-1$ year), and to evaluate factors influencing kitten survival. We analyzed long-term radio-telemetry 
(1982-2008) and Passive Integrated Transponder (PIT)-tagging (1995-2008) data within a liverecapture, dead recovery modeling framework (Burnham 1993; Williams et al. 2002). We tested the hypotheses that kitten survival: (1) would not differ between sexes, due to little or no sexual dimorphism during this stage of life; (2) would decrease with increasing litter size due to large litters potentially being more energetically demanding to dams and more difficult to protect from predators; (3) would be higher during the wet season (June - November) than during the dry season (December - May), due to potential higher prey availability during the wet season; and (4) would be negatively influenced by population abundance due to densitydependent effects. In many species of carnivores, survival of neonates is generally lower compared to older juveniles (Garrison et al. 2007; Logan and Sweanor 2001). Thus, we also hypothesized that kitten survival (5) would increase with age during their first year.

Results of rigorous analyses evaluating the effects of genetic introgression on kitten survival could assist in setting future management and research priorities. Thus, we tested these additional hypotheses: (6) kitten survival probability would increase with average heterozygosity, because loss of genetic variation (especially due to inbreeding) has been shown to negatively influence fitness and its components (Crnokrak and Roff 1999; Ralls and Ballou 1983); and (7) survival probability would be higher for admixed kittens than for canonical (i.e., pure Florida panther) kittens as outcrossing has been shown to increase various measures of fitness for small, inbred populations (Heschel and Paige 1995; Madsen et al. 1999; Vrijenhoek 1994).

\section{Materials and methods}

\subsection{Field methods}

Florida panthers and Texas pumas were captured and monitored by radio-telemetry from 1982-2008 across the range of the subspecies in south Florida, USA (Kautz et al. 2006) by biologists from the FWC and National Park Service (NPS) using methods described by Belden et al. (1988) and Land et al. (2008). Age of captured panthers (if unknown) was estimated using a combination of toothwear, pelage characteristics, size, and developmental stage of teats and reproductive organs. Blood and tissue samples were collected for health assessment and genetic analysis. Radio collars were affixed on captured adults, sub-adults, and older kittens (occasionally as young as 5 months old; age and size qualifications for collaring varied over time).

Successive locations of females were continually assessed to determine the commencement of denning behavior; lack of movement between 3-4 fixes was taken as evidence of possible denning (Land et al. 1998). We visited dens 4-35 days post-partum (approximate median $=14$ days). Kittens in dens were counted, sexed, sampled for genetic material, and implanted with passive integrated transponder (PIT) tags. Occasionally, dens were checked after dams vacated the area for evidence of dead kittens.

Females that denned $\leq 12$ months after giving birth to a previous litter were classified as having lost that previous litter because 1) females are unlikely to copulate while they have dependent kittens, 2) the gestation period is about 3 months (Maehr 1992), and 3) the minimum age of independence recorded is 9 months (D. Onorato, unpubl. data). Similarly, litters whose dams died $\leq 9$ months after denning were classified as having failed. These two types of litter failure data generally do not provide an estimated death date for individual kittens, only an upper limit on the date when litters could have failed. 


\subsection{Heterozygosity and genetic ancestry}

We extracted total genomic DNA from blood and tissue samples obtained from wild-caught panthers and captive pumas from south Florida and west Texas during 1982-2007. We amplified and scored 23 microsatellite loci following previously described PCR amplification conditions (Menotti-Raymond et al. 1999; Menotti-Raymond et al. 1997). Derived genotypes were used to calculate average individual heterozygosity using the program MICROSAT (Minch et al. 1995).

A Bayesian procedure, implemented in the program STRUCTURE (Pritchard et al. 2000) was used to identify populations or genetic clusters (run without preset groups/training individuals) and to estimate the genetic origin of individuals. The STRUCTURE approach assumes departures from both Hardy-Weinberg and complete linkage equilibriums to be indications of population substructure (Pritchard et al. 2000).

We used results from the STRUCTURE analysis along with pedigree information and field evidence to assign panthers to groups that reflect the genetic makeup of the southern Florida population: canonical panthers (92 total panthers; 50 kittens), backcrossed to canonical admixed panthers (92 total panthers; 80 kittens), backcrossed to Everglades admixed panthers (19 total panthers; 18 kittens), backcrossed to Texas admixed panthers (42 total panthers; 38 kittens), and $\mathrm{F}_{1}$ admixed panthers (15 total panthers; 13 kittens). Canonical Florida panthers showed no evidence of non-Florida genetic admixture (no direct non-Florida relatives or < $10 \%$ non-Florida genetic contribution based on STRUCTURE analyses). Admixed panthers were mostly the descendents of the introduced female Texas pumas released in 1995, except for 6 radio-collared individuals ( 0 kittens) that were genotypically similar to pumas maintained in a large enclosure on the Seminole Indian Reservation (SIR) adjacent to Big Cypress National Preserve. These SIR panthers, panthers of unknown ancestry (4 kittens), and admixed panthers whose ancestry could not be accurately determined (total $=54$, of which 43 were kittens) were excluded from the survival analysis that incorporated ancestry.

Backcrossed to canonical panthers were admixed panthers with predominantly (>50\%) canonical heritage resulting from admixed panthers breeding with canonical panthers. Backcrossed to Everglades were admixed panthers with predominantly ( $>50 \%)$ Everglades heritage resulting from breeding events between admixed and Everglades panthers.

Backcrossed to Texas admixed panthers were admixed panthers of predominantly ( $>50 \%)$ Texas heritage resulting from admixed panthers breeding with introduced Texas pumas. We defined $F_{1}$ admixed panthers as any offspring produced by matings between a Texas female and a pre-introgression type male (either canonical Florida panther or Everglades panther). In theory, Everglades panthers (with documented genetic links to Central American pumas) represent a sixth genetic population; however, there were no recorded kittens of this group during the post-introgression study period (June 1995 - May 2008).

We also repeated our analyses based on a simpler ancestry classification (canonical, $\mathrm{F}_{1}$ admixed, and other admixed) that allowed the inclusion of admixed panthers with unknown ancestry; results of these analyses are presented in Appendix A.

\subsection{Index of abundance}

To examine the potential effects of panther density on kitten survival, we used minimum population counts as an index of abundance (McBride et al. 2008). These minimum counts were based on radio-tracking and field evidence of sub-adult and adult panthers (tracks, scat, kills, and scrapes) and collected for calendar years (e.g., total number of sub-adult and adult panthers known to have been alive in the wild over the period January 2005 - December 2005). In contrast, we analyzed annual kitten survival for periods extending from June - May. We 
applied the sub-adult/adult calendar year count for year $x$ to the kitten June $x$ - May $x+1$ year, because puma kitten mortality is generally highest in the first three months of life (see Results), so adult abundance during that period seemed most likely to affect survival. In 2004, the panther survey was incomplete, so the minimum count is unknown. We followed McBride et al. (2008) and extrapolated it halfway between the 2003 and 2005 counts.

\subsection{Data preparation and analysis}

We used two datasets for the analysis of kitten survival. The first contained the capture (of live panthers) and recovery (of dead panthers) histories, observations of litter-failures (i.e., loss of entire litters), and radio-tracking data for panthers that were initially PIT-tagged in the den between June 1995 and May 2008 (13 years). The second contained the capture, recovery, and radio-tracking histories of all other panthers between n June 1982 and May 2008 (26 years). Details of data preparation can be found in Appendix B.

We analyzed data using the R (R Development Core Team 2010) package RMark (Laake and Rexstad 2010) as an interface for program MARK (White and Burnham 1999) and Burnham's live-recapture dead-recovery modeling framework (Burnham 1993; Williams et al. 2002). The Burnham model has four parameters: survival probability $(S)$, recapture probability $(p)$, recovery probability $(r)$, and fidelity $(F)$. For all models, we fixed $F=1$ for all panthers, as the recapture and recovery areas are the same and encompass the entire range of the Florida panther. We set $p$ and $r$ for radio-collared animals to 1 , because we could count on knowing their status each year.

Although the focus of our study was kitten survival, we also used data from sub-adult and adult panthers to efficiently parameterize the likelihood functions. For example, the likelihood of a kitten being PIT-tagged in the den and then recaptured as a 2-year old panther depends on the probability of it surviving as a kitten, the probability of it surviving the first year of being a sub-adult, and the probability of recapture as a sub-adult. Thus, to estimate the kitten survival probability from data such as these, we also need to estimate the other aforementioned probabilities. We used a model with an interaction of sex and age class (sub-adult or adult), a reasonably well supported model (Benson et al. 2009) that could be applied to all individuals, to estimate the survival of sub-adults and adults. The boundary between sub-adult and adult panthers was originally defined at age 2.5 for females and age 3.5 for males (Benson et al. 2009). Transitions at these ages were impossible with a one-year time step; therefore, we fitted survival models with those ages rounded up and down to the nearest integer (to 2 and 3 for females and 3 and 4 for males). We used an information-theoretic approach (Akaike's Information Criterion adjusted for overdispersion and small sample size; $\mathrm{QAIC}_{\mathrm{c}}$ ) for model selection and statistical inference (Burnham and Anderson 2002). We calculated QAIC $\mathrm{c}_{\mathrm{c}}$ values, Akaike differences $\left(\triangle \mathrm{QAIC}_{\mathrm{c} i}\right.$, difference between $\mathrm{QAIC}_{\mathrm{c}}$ value of the $i$ th model and the topranked model) and Akaike weights (the weight of evidence that a model is the best model of the models being considered given the data) as in Burnham and Anderson (2002). We calculated model-averaged estimates of annual survival and unconditional variance for each level of categorical variables and across continuous covariates (Burnham and Anderson 2002; Tinker et al. 2006). To generate these model-averaged estimates of survival we used all models included in the model selection process for a given analysis, with model-specific estimates weighted by their Akaike weights. Models with no effects of the covariates being presented were included in the averages.

We commenced by testing all a priori models for recapture and recovery combined with $a$ priori models for survival of kittens, sub-adults, and adults with various divisions of age classes. Because kittens could only be recaptured as sub-adults the following year, there was no capture probability parameter for kittens (e.g., Pollock 1981); for sub-adult and adult panthers we estimated a single capture probability. We used models that estimated separate 
recovery rate for kittens and older panthers as well as those that estimated a single recovery rate for all panthers.

We used a model that allowed kitten survival to vary between sexes and recapture probability to be different for kittens (the most parameterized model that applies to the full dataset) to test for overdispersion of the data due to lack of independence within litters $(\hat{c})$ using the data bootstrap approach developed by Bishop et al. (2008); a $\hat{c}>1$ indicates overdispersion. We estimated $\hat{c}$ as the ratio of the replication-based estimate of the variance of bootstrapped survival estimates (this variance incorporates overdispersion associated with lack of independence) to the model-based estimate of variance of survival (estimated from the original dataset). For the bootstrap approach, we sampled litters from the dataset with replacement. Panthers first captured as sub-adults or adults were treated as litters of size 1 for the bootstrapping. If the model failed to estimate kitten survival parameters, the iteration was discarded. We repeated the resampling and estimation until we had 1,000 estimates of female and male kitten survival and estimated the mean $\hat{c}$ as in Bishop et al. (2008). The estimate of overdispersion was 1.37 for females and 1.60 for males, with a mean $\hat{c}$ of 1.48 , indicating slight overdispersion of data. We used this value as a variance inflation factor and to calculate $\mathrm{QAIC}_{\mathrm{c}}$.

We selected the model with the lowest $\mathrm{QAIC}_{\mathrm{c}}$ from preceding analyses as the base model to test hypotheses regarding factors affecting kitten survival (Table 1). The models for ancestry (Table 1A, models 3-6, Table 1B) and heterozygosity (Table 1A, models 7-10) were run on data collected between 1995 and 2008 only due to the absence of admixed panthers in Florida before 1995. We tested for the effect of ancestry and heterozygosity on survival of (1) kittens only; (2) sub-adult and adult panthers only; (3) kittens and older panthers considered separately; and (4) panthers of all ages. Based on previous results (Benson et al. 2009), however, we only considered 2 ancestry categories for sub-adult and adult panthers (F1Adv; Table 1B).

We tested for the effect of abundance on kitten survival (Table 1A, model 11) using data collected between 1995 and 2008. Data on kittens collected prior to 1995 were insufficient to test for the effect of abundance on kitten survival.

Finally, we estimated process variance (random effect of year; a critical parameter for stochastic population models) in kitten survival using the Markov Chain Monte Carlo (MCMC) option in MARK (Lukacs et al. 2009; White et al. 2009). We used the Bayesian MCMC approach instead of a method of moments approach because some missing kitten survival estimates for specific years (fixed effects categorical model used as an input for method of moments) made the method of moments approach unreliable (G. White pers. comm.). We estimated process standard deviation in logit survival from the mean and $95 \%$ credible interval of the posterior distribution. To estimate the temporal variation beyond that explained by abundance, we also estimated the temporal standard deviation associated with year in the model that included abundance index as a covariate. Temporal standard deviations were converted from the logit scale using the mean kitten survival (to $\hat{\sigma}$; without abundance index model) and the kitten survival computed for the mean abundance (to $\sigma_{\text {res }}$; abundance index model). We estimated percentage of the temporal variance explained by abundance as $\left(\widehat{\sigma}^{2}-\sigma_{\text {res }}^{2}\right) / \widehat{\sigma}^{2}$ (Loison et al. 2002).

We used the same non-informative priors as White et al. (2009); estimates from the fixed effects models were used as starting values where appropriate. We tested for lack of convergence using 10 Markov chains for each model (Gelman 1996) and found no evidence of lack of convergence. For each chain we sampled the MCMC for 50,000 iterations, after 4,000 tuning samples and 1,000 burn-in samples. 


\subsection{Three-month time step data preparation and analysis}

Using the data organized on an annual time scale, it was not possible to test for seasonal variation in kitten survival and age-specific variation in survival within the first year of life. Therefore, we recoded data into 3-month time intervals. This necessitated leaving out litter failure data, because information about the 3-month interval in which actual kitten deaths occurred was generally not available from these data. We also did not include the recapture/ recovery histories of panthers not PIT tagged in the den (without working radio-collars), for computation efficiency (Appendix C).

Analysis of the data with a 3-month time step was similar to the annual time step analysis, except that there was now a possibility of recapture as a kitten. We commenced by testing all a priori models for recapture and recovery combined with a priori models for survival of kittens based on age (Appendix C). We report model-specific and model-averaged estimates of annual kitten survival probability and model-averaged estimates of 3-month kitten and annual subadult and adult survival probabilities (Burnham and Anderson 2002).

\section{Results}

The most parsimonious model (model 1, Table 2) indicated that survival $(S)$ and recapture $(r)$ probabilities differed between kittens and older panthers, and that $S$ differed between sex and age classes among older panthers, with the sub-adult to adult transition at the upper age limit for both sexes. The four models with lowest $\mathrm{QAIC}_{\mathrm{c}}$ provided similar estimate of kitten survival (Table 2); the model-averaged estimate of annual kitten survival was $0.323 \pm 0.071$ ( $\pm 1 \mathrm{SE}$ ).

We selected the most parsimonious model from the initial model set (model 1, Table 2) as a base model for testing the effects of covariates on kitten survival. There was no evidence of an effect of sex (Table 2$)$ or litter size $\left(\Delta \mathrm{QAIC}_{\mathrm{c}}\right.$ of litter size model $\left.=2.04\right)$ on kitten survival.

Two of the ancestry models (base $+\mathrm{k}:$ CanDisF1Adv and base $+\mathrm{k}: \mathrm{F} 1 \mathrm{Adv}$ ) failed to estimate a kitten survival parameter and were discarded. There was considerable evidence that ancestry influenced kitten survival; the 6 most parsimonious models all included ancestry effects on kitten survival (models 1-6, Table 3A). The top 2 models indicated that survival of kittens differed substantially between two ancestry categories: 1) canonical and backcrossed to canonical kittens and 2) $F_{1}$, backcrossed to Texas, and backcrossed to Everglades kittens (Table $3 \mathrm{~A}$ ). Model-averaged kitten survival was lowest for canonical kittens and highest for $\mathrm{F}_{1}$ kittens (Figure 1A).

The most parsimonious model including the effects of heterozygosity on survival indicated that survival of panthers of all ages (including survival of kittens) was positively affected by average heterozygosity (Table 3B, model 1). Although this model differed from the base model by $\Delta$ QAIC $_{\mathrm{c}}<2$, the $95 \%$ confidence interval for the slope parameter did not include zero $(\beta=$ $2.89 ; 95 \%$ CI: $0.16-5.63$ ) suggesting a positive effect of average heterozygosity on panther survival. Model-averaged kitten survival increased with heterozygosity (Figure 1B).

There was considerable evidence that abundance negatively influenced kitten survival, with the model with no such effect having a $\Delta$ QAIC $_{\mathrm{c}}$ of 8.79 (Table 3C). Kitten survival declined with increasing population size (Figure 2; $\beta=-0.034,95 \% \mathrm{CI}=-0.053--0.016$ ).

We estimated temporal standard deviation of kitten survival $(\sigma)$ at 0.228 (95\% credible interval $=0.019-0.431)$ and $0.098(95 \%$ credible interval $=0.004-0.286)$ using models without and with the abundance index, respectively. Abundance index explained $81.5 \%$ of the temporal variation in kitten survival. 
There was considerable uncertainty in the base model selection, with 8 models in Table 2 having $\Delta \mathrm{QAIC}_{\mathrm{c}}<1$. We reran all covariate tests using model 5 from Table 2 as a base model (model 5 was the highest ranked model with a different estimate of kitten survival than model 1). Model selection and statistical inference were barely affected by the switch of base models, and model averaged estimates that included both sets of models were somewhat lower, but generally had similar precision (Appendix D).

There was strong evidence that kitten survival was lowest in the first 3 months of life (Figure 3). There was no evidence for seasonal variation in kitten survival (Appendix C). Details of results based on the analysis of data organized using 3-month time steps are presented in Appendix C.

\section{Discussion}

Models developed for population conservation and management have historically focused on either population dynamics (Morris and Doak 2002) or threshold numbers required to avoid genetic problems (Franklin 1980). The population ecology and population genetics of a species are frequently not integrated in these models. When they are, the demographic effects of inbreeding are often based on data from captive animals and/or program defaults (e.g., Brito 2009; Maehr et al. 2002; Nilsson 2004). An important first step towards developing integrated models is determining the functional relationship between measures of inbreeding and juvenile survival in the wild, especially for managed populations.

Overall, the model-averaged estimate of annual survival probability of Florida panther kittens was $0.323 \pm 0.071$; this estimate is lower than those reported for western North American populations of pumas (range: 0.44 to 0.72; Lambert et al. 2006; Laundré et al. 2007; Logan and Sweanor 2001; Robinson et al. 2008). Our estimate of kitten survival also is substantially lower than those used in earlier demographic analyses of the Florida panther (Maehr and Caddick 1995: 0.84 - 0.87; Maehr et al. 2002: 0.735 - 1.0; Root 2004: 0.62). Although our estimates of kitten survival varied slightly depending on the model ( 0.30 to 0.34 ; Table 2$)$, they were consistently lower than those used in previous analyses. Furthermore, kittens were not tagged immediately after birth, and we could have missed kittens that had died before they were PIT-tagged at the den site; thus, true survival may be slightly lower. However, since most of our data on kitten survival came from a period of population growth (McBride et al. 2008), we have no reason to believe that the kitten survival rate for this population is unsustainable. Ongoing work developing updated population models for Florida panthers may shed additional light on the role of kitten survival in determining population dynamics.

Survival rates did not differ between male and female kittens. This result was as expected due to the lack of sexual dimorphism among kittens, although some authors have suggested sexspecific differences in survival of puma kittens (Logan and Sweanor 2001). There was no evidence that litter size influenced survival of kittens. This may reflect the possibility that females most able to successfully raise large litters are those most likely to produce them.

Perhaps the most dramatic panther conservation measure undertaken to date is the release of 8 female Texas pumas into the Florida panther population in 1995 (Seal 1994). Genetic introgression has been highly controversial (e.g., Maehr and Caddick 1995; Maehr et al. 2006; Pimm et al. 2006). Pimm et al. (2006) reviewed the arguments for and against genetic introgression in general, and in the Florida panther population in particular. They reported that admixed kittens are more than three times as likely to survive as purebred Florida panthers. Pimm et al's (2006) conclusions were based solely on the proportion of kittens PIT-tagged in the den that were subsequently captured and (generally) radio-collared. These kittens were 
recaptured at ages ranging from 6.5 months to 3.5 years and detection probability was not taken into account, so it is unclear how well these ratios represent differences in kitten survival.

In the present study, we used multiple sources of field data, a thorough determination of ancestry of nearly all kittens captured since genetic introgression occurred in 1995, and a statistically rigorous live-recapture dead-recovery modeling approach that takes detection probabilities into account to test for the effect of genetic introgression on the survival of Florida panther kittens. As recommended by Creel (2006), we limited this portion of the analysis to a period when both canonical and admixed kittens were on the landscape. We also were able to examine the effects of heterozygosity, which differed dramatically between canonical Florida panthers (0.161) and Texas pumas (0.318; Driscoll et al. 2002; W. Johnson, unpubl. data). Furthermore, we were able to determine ancestry of panther kittens at a much finer scale than Pimm et al. (2006). We found that admixed kittens generally survived better than kittens born to canonical Florida panthers. Furthermore, $F_{1}$ admixed kittens had the highest survival, followed by backcrossed to Texas kittens (Fig. 1A). Finally, we found that average heterozygosity positively influenced survival of Florida panther kittens (Fig. 1B). These results provide unambiguous evidence for the positive, population-level impact of genetic introgression.

Index of panther abundance negatively influenced kitten survival, which is suggestive of a density dependent effect. This could result from infanticide by sub-adult and adult males during territorial disputes or for mating opportunities (Garrison et al. 2007; Logan and Sweanor 2001; Packer et al. 2009), from deaths of the dependent kittens' dams due to intraspecific aggression, or from competition for food or other resources. We note, however, that our results are based on an index of abundance, and thus may not be sufficient to conclusively demonstrate density-dependent influence on kitten survival. Interestingly, a substantial proportion of temporal variation in kitten survival was explained by temporal variance in index of abundance.

Analysis of data organized with 3-month time intervals revealed no evidence for seasonal (i.e., wet vs. dry) variation in survival of kittens. However, we found that survival was lowest during the first 3 months of life, which is consistent with other large carnivore populations (Garrison et al. 2007; Logan and Sweanor 2001). These results point to the fact that young kittens are particularly vulnerable to various mortality factors.

Estimating survival of young can be challenging in elusive carnivores because they are rarely observed. Additionally, in the case of panthers, kittens are typically too small to be fitted with radio-transmitters when sampled at the den site - a method that would be effective for monitoring their fate during the first year of life. Furthermore, the small population size of endangered species and invariably small sample sizes may not be adequate for rigorous estimates of survival of the young. For example, estimates of kitten survival that did not include litter failure data lacked robustness as well as precision; models that were similarly ranked based on $\mathrm{QAIC}_{\mathrm{c}}$ provided very different estimates of kitten survival (Appendix C). We addressed this challenge by using a modeling framework that can utilize multiple data sources. Resulting estimates of kitten survival were more robust and precise, and also allowed us to test various hypotheses regarding factors influencing survival of Florida panther kittens. Similar approaches can be used to estimate survival of young in other elusive species that occur in low numbers.

Our study is the first to provide rigorous estimates of survival of Florida panther kittens. We found that kitten survival in our study population was lower than reported for western cougars, and substantially lower than values used in previous demographic analyses of Florida panthers. These results are consistent with an earlier suggestion that results of a previous PVA (Maehr et al. 2002) that assumed kitten survival of up to $87 \%$ may be unreliable (Beier et al. 2003). 
Finally, we found strong evidence that survival of admixed (particularly, $\mathrm{F}_{1}$ ) kittens was substantially higher than that of purebred kittens, and that heterozygosity positively influenced survival of Florida panther kittens. These results are consistent with hybrid vigor theory (Crow 1948; Frankham et al. 2002), and suggest that genetic introgression had positive populationlevel effects in our study population. Although there are concerns that genetic introgression can have undesirable or even negative impacts on populations (Edmands 2007; Maehr and Caddick 1995; Shields 1993), our analyses revealed beneficial results of deliberate

introgression for this population. A combination of these results with other recently published or on-going assessments of demography pre- and post-introgression should assist in directing management and research priorities that will ensure the continued persistence the critically endangered Florida panther.

\section{Appendix A}

\section{Analysis of Florida Panther Kitten Survival Based on 3 Ancestry Categories}

\section{Methods}

We used results from the STRUCTURE analysis along with pedigree results and field evidence to assign panthers to 3 groups that reflect the genetic makeup of the southern Florida population (canonical panthers, $\mathrm{F}_{1}$ admixed panthers, and other admixed panthers). Canonical and $\mathrm{F}_{1}$ admixed ancestry categories are defined in the main text. The other admixed category includes: backcrossed to canonical (admixed panthers with predominantly (>50\%) canonical heritage); backcrossed to Everglades (admixed panthers with predominantly $(>50 \%)$ Everglades heritage resulting from breeding events between Texas admixed and Everglades panthers); backcrossed to Texas (admixed panthers of predominantly $(>50 \%)$ Texas heritage resulting from admixed panthers breeding with introduced Texas cougars); unknown admixed; and Seminole admixed panthers (these last two categories were not included in the analyses presented in the text). Based on these 3 ancestry categories, we formulated alternative hypotheses regarding the effect of ancestry on kitten survival (Table A1).

We selected model 1 in Table 4 as the base model because this model had the lowest QAIC $_{\mathrm{c}}$ among candidate models (Table 4), and used model selection to draw inferences for hypotheses about the effects of ancestry on kitten survival (Table A1). For these analyses, we used a subset of data collected between 1995 and 2008, due to the absence of admixed panthers in Florida before 1995. We tested for the effect of ancestry on survival of (1) kittens only; (2) sub-adult and adult panthers only; (3) kittens and older panthers considered separately; and (4) panthers of all ages. Based on previous results (Benson et al. 2009), however, we only considered 2 ancestry categories for sub-adult and adult panthers (Ancest2; Table A1). We report modelaveraged annual estimates of kitten survival probability (Burnham and Anderson 2002).

\section{Results and Discussion}

Three models (base $+\mathrm{k}$ :Ancest1, base $+\mathrm{k}$ :Ancest $1+\mathrm{s} \& \mathrm{a}$ :Ancest2, and base $+\mathrm{k}$ :Ancest2) failed to estimate a kitten survival parameter and were discarded. The most parsimonious model testing for the effect of simple ancestry on survival indicated that survival of panthers of all ages (including survival of kittens) was higher for $F_{1}$ admixed (Table A2, model 1). Although this model differed from the model where ancestry only affects the survival of sub-adults and adults (model 3 ) by $\triangle \mathrm{QAIC}_{\mathrm{c}}<2$, the $95 \%$ confidence interval for the slope parameter did not include zero ( $\beta=1.55 ; 95 \%$ CI: $0.46-2.65$ ) providing strong evidence of a difference between the survival of $F_{1}$ admixed and other panthers. Model-averaged estimated kitten survival increased from canonical to other admixed to $F_{1}$ admixed panthers (Figure A1). 
These results suggest that although there are subtle differences in survival of kittens with various genetic ancestries, the main difference is that between F1 admixed kittens and those of all other ancestry categories. F1 admixed kittens survived substantially better than kittens with other ancestry categories. This F1 admixed kitten survival advantage was also found in the ancestry analysis presented in the text. One difference in that analysis is that we found that some of the other admixed categories (specifically backcrossed to Texas and possibly backcrossed to Everglades) also had higher survivals than the canonical kittens. We believe that those results represent real differences within the other admixed category, and are not an artifact of the exclusions required for that analysis.

\section{Table A1}

Definitions of simple ancestry models, and the hypotheses they represent.

\begin{tabular}{lll}
\hline Term & Definition & Hypothesis \\
\hline Ancest1 & 3 ancestry categories: 1) Canonical; 2) Other Admixed; and 3) $\mathrm{F}_{1}$ Admixed. & $\begin{array}{l}\text { Different survival probability } \\
\text { for each ancestry group. }\end{array}$ \\
Ancest2 & 2 ancestry categories: 1$)$ Canonical and Other Admixed; and 2) $\mathrm{F}_{1}$ Admixed. & $\begin{array}{l}\text { First generation survival } \\
\text { advantage (or disadvantage). }\end{array}$ \\
Ancest3 & 2 ancestry categories: 1) Canonical; and 2) Other Admixed and $\mathrm{F}_{1}$ Admixed. & $\begin{array}{l}\text { General admixed survival } \\
\text { advantage (or disadvantage). }\end{array}$ \\
\hline
\end{tabular}

\section{Table A2}

Model selection table for testing hypotheses regarding the effect of genetic ancestry on survival of kittens and older panthers based on 3 ancestry categories. These analyses were performed on a subset of the data (excluding panthers before 1995 and panthers of unknown ancestry). For each model, we present the number of parameters $(\mathrm{K})$, the difference from the top model in Akaike's Information Criterion adjusted for small sample size and overdispersion $\left(\triangle \mathrm{QAIC}_{\mathrm{c}}\right)$, and the model $\mathrm{QAIC} \mathrm{c}_{\mathrm{c}}$ weight. See Table A1 for descriptions of the covariate models and Table 4 for the base model. All models estimate constant recapture rates and recovery rates that differ between kittens and older panthers $(p() r.(\mathrm{k}, \mathrm{s} \& \mathrm{a}))$. Model 1 in Table 2 was used as the base model for these analyses. Ancestry categories are defined in Table A1.

\begin{tabular}{llcl}
\hline Survival Model & K & $\Delta$ QAIC $_{\mathbf{c}}$ & Weight \\
\hline 1. base + Ancest2 & 9 & 0.00 & 0.367 \\
2. base + Ancest1 & 10 & 1.15 & 0.207 \\
3. base + s\&a:Ancest2 & 9 & 1.86 & 0.145 \\
4. base + k:Ancest2 + s\&a:Ancest2 & 10 & 2.04 & 0.132 \\
5. base + k:Ancest3 + s\&a:Ancest2 & 10 & 2.52 & 0.104 \\
6. base + Ancest3 & 9 & 5.81 & 0.020 \\
7. base & 8 & 6.46 & 0.015 \\
8. base + k:Ancest3 & 9 & 6.91 & 0.012 \\
\hline
\end{tabular}

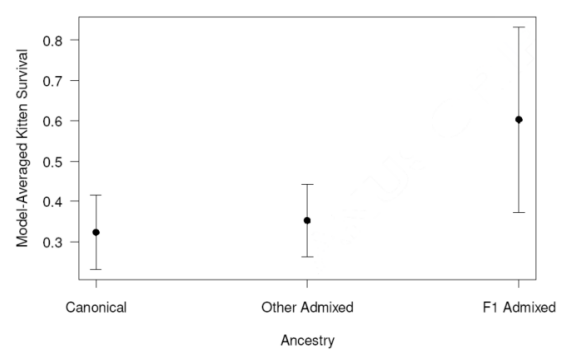

Biol Conserv. Author manuscript; available in PMC 2011 November 1. 
Figure A1.

Model-averaged estimates of annual survival of Florida panther kittens based on 3 ancestry categories (Table A1). Error bars represent unconditional estimated standard errors.

\section{Appendix Literature Cited}

Benson, JF.; Hostetler, JA.; Onorato, DP.; Johnson, WE.; Roelke, M.; O’Brien, SJ.; Jansen, D.; Oli, MK.
Survival and cause-specific mortality of sub-adult and adult Florida panthers. In: Hostetler, JA.;
Onorato, DP.; Oli, MK., editors. Population ecology of the Florida panther. The Florida Fish and
Wildlife Conservation Commission and The US Fish and Wildlife Service; 2009. p. 10-61.
Burnham, KP.; Anderson, DR. Model selection and multimodel inference. 2. Springer; New York: 2002.

\section{Appendix B}

\section{Data Preparation}

We used two datasets for the analysis of kitten survival. The first contained the capture (of live panthers) and recovery (of dead panthers) histories, observations of litter-failures (i.e., loss of entire litters), and radio-tracking data for panthers that were initially PIT-tagged in the den between June 1995 and May 2008 (13 years). The second contained the capture, recovery, and radio-tracking histories of all other panthers between June 1982 and May 2008 (26 years). We used a live-dead data input format (Cooch and White 2008).

We coded the data with a 1-year time step. All litter failures were treated as recoveries within the first year, because all known litter failures occurred within the first year of kittens' lives (after which the kittens' fates were considered to be independent of their dams'). For panthers that were not PIT-tagged in the den, captures and radio-failures were coded as occurring on the closest June 1, and known deaths were coded as occurring in the June-May interval in which they occurred. PIT-tagging events of kittens in the den were also coded as occurring on the closest June 1. Subsequent captures, radio-failures, and known deaths of that group were coded to happen at the correct age, rather than the correct year, on the occasions when those were in conflict.

Panthers that would have died if we had not removed them to captivity were treated as having died on the date of removal. One exception was a panther whose injuries were apparently capture related; it was right-censored on the capture date and added again to the analysis on the date it was returned to the wild. Kittens that were found dead during the initial den visit $(n=7)$ were not included in the survival analysis, but were included in the litter size counts of PIT-tagged kittens in their litters.

The ages of 91 radio-collared panthers not handled as kittens in the den were estimated as previously described; 11 were estimated to be $<1$ year of age. When ages were estimated as a range in the field (e.g., 5-6 years old), we used the average of the range for assigning age class transitions. The influence of estimated age on the estimates of survival of adult panthers was insubstantial (Benson et al. 2009: Appendix A); this effect is likely even smaller for survival of kittens.

The sex of two kittens from a single litter was not recorded in the field; since their fates were the same and the overall numbers of kittens PIT-tagged for each sex were similar (119 females and 131 males), we randomly assigned one as a female and the other male. We did not have covariate data for all panthers included in the analyses. Thus, we tested for the effect of litter size and ancestry on survival separately after excluding kittens or all panthers, respectively, with missing values. For average heterozygosity, we ran a separate analysis excluding panthers that had not been genotyped, as well as captures of panthers that occurred before they were 
successfully genotyped. This approach removed the potential bias in survival estimates by heterozygosity that would be caused by only excluding those that were never genotyped (Nichols et al. 2004).

\section{Appendix Literature Cited}

Benson, JF.; Hostetler, JA.; Onorato, DP.; Johnson, WE.; Roelke, M.; O’Brien, SJ.; Jansen, D.; Oli, MK. Survival and cause-specific mortality of sub-adult and adult Florida panthers. In: Hostetler, JA.; Onorato, DP.; Oli, MK., editors. Population ecology of the Florida panther. The Florida Fish and Wildlife Conservation Commission and The US Fish and Wildlife Service; 2009. p. 10-61.

Cooch, E.; White, GC., editors. Program MARK - 'a gentle introduction'. 72008. http://www.phidot.org/software/mark/docs/book/.

Nichols JD, Kendall WL, Hines JE, Spendlow JA. Estimation of sex-specific survival from capturerecapture data when sex is not always known. Ecology 2004;85:3192-3201.

\section{Appendix C}

\section{Analysis of Survival of Florida Panther Kittens Using Data Organized in 3- month Time Steps}

\section{Methods}

Using the data organized on an annual time scale, it was not possible to test for seasonal variation in kitten survival and changes in survival within the first year of life. Therefore, we recoded the data with 3-month time steps. This necessitated leaving out litter failure data, because the 3-month interval in which actual kitten deaths occurred was generally not available from these data. The large number of capture occasions $(26 * 4=104)$ made it computationally necessary to divide the sampling period in half. All data from panthers PIT tagged in the den were in the second half and could be handled normally, but all other panthers were only followed while radio-collared to accommodate the half transition. The analyses of data organized in 3-month time step also allowed us to compare sub-adult and adult survival with the results of Benson et al. (2009), because we were now able to put the transition from subadult to adult at the same age as in their analyses (2.5 years old for females and 3.5 years old for males).

Analysis of the data with a 3-month time step was similar to the annual time step analysis, except that there was now a possibility of recapture as a kitten. We set recapture probability $(p)$ and recovery probability $(r)$ for radio-collared animals to 1 , and $p$ for 3 -month old panthers to 0 , because none of the few panthers captured and radio-collared at $<6$ months of age were PIT-tagged first. The FWC and National Park Service (NPS) instituted a policy in November 2001 restricting the capturing and radio-collaring of kittens $<12$ months in age. Therefore we fixed $p$ at 0 for 6-month old kittens starting at that date.

Data analysis proceeded as described in the text. We commenced by testing all a priori models for recapture and recovery combined with a priori models for survival of kittens based on age (Table C1). The kittens of Texas cougars may have been more likely to be captured than other kittens, due to greater efforts expended to capture those kittens (model 1, Table C1A). The justification for the separate recovery rate for kittens $\leq 3$ months of age (models 4 and 5, Table C1B) is that a different series of events leads to recovery of kittens in the den (approximately the first 7-8 weeks, Maehr et al. 1990) compared to older panthers. For a kitten in the den to be recovered, it has to be PIT-tagged, die, and then be found in a subsequent visit to the den. For an older (non-radio-collared) panther that was handled and marked with a PIT tag as a kitten to be recovered, it has to die (most likely due to a vehicle collision), and subsequently be reported to panther researchers. A cause-specific mortality analysis of radio-collared sub- 
adult and adult panthers suggests that the probability of a panther's death being due to vehicular collision is independent of sex or age class (Benson et al. 2009).

We tested all combinations of survival, recapture, and recovery models from Table $\mathrm{C} 1$ and selected the most general model that converged successfully (if there was a tie, we selected the model with the lowest $\mathrm{AIC}_{\mathrm{c}}$ ). We used that model to test for overdispersion of the data due to lack of independence within litters using a data bootstrap (Bishop et al. 2008). We sampled litters from the dataset with replacement. Panthers first captured as sub-adults or adults were treated as litters of size 1 for the bootstrapping. We estimated annual survival of kittens as a derived parameter of the model. If the model failed to estimate any parameters, the iteration was discarded. We repeated the resampling and estimation until we had 1,000 estimates of kitten survival. We calculated the mean and standard deviation of the estimates, and estimated the overdispersion parameter $(\hat{c})$ as [(bootstrap standard deviation of estimates of kitten survival) / (standard error of kitten survival obtained from the original model run) $]^{2}$. An estimated $\hat{c}>1$ indicates overdispersion. We used the estimated $\hat{c}$ to calculate the QAICc for each model and as a variance inflation factor.

We selected the model or set of models with the lowest QAIC $_{\mathrm{c}}$ as the base model(s) to test our hypothesis that kitten survival varies seasonally. We report model-specific and model-averaged 3 -month and annual estimates of kitten survival probability and model-averaged estimates of recapture, recovery, and sub-adult and adult survival probabilities (Burnham and Anderson 2002).

\section{Results and Discussion}

Of the 72 models run (all permutations from Table $\mathrm{C} 1$ ), 14 failed to estimate all parameters and were discarded, including all models using survival model 7 (Table C1C). From the most general models remaining (with 13 parameters), the model $S(\mathrm{k}<3,3 \leq \mathrm{k}<9, \mathrm{k} \geq 9) p(\mathrm{k}: \mathrm{DO}, \mathrm{s} \& \mathrm{a})$ $r(\mathrm{k}<3, \mathrm{k} \geq 3, \mathrm{~s} \& \mathrm{a})$ had the lowest $\mathrm{AIC}_{\mathrm{c}}$ and was used in the litter bootstrap to estimate $\hat{c}$. We estimated $\hat{c}$ at 2.20 , which is only slightly less than the average litter size of PIT tagged kittens used in the analysis (mean litter size $=2.47$ ).

There was strong support for kitten survival being lowest in the first 3 months of life (Table C2; main text Figure 1). Several closely ranked models yielded very different estimates of annual kitten survival, and variances of most estimates were substantial (Table C2, Fig. C1). These results suggest that estimates of kitten survival obtained from data organized in 3 monthtime steps lacked precision and robustness, most likely due to sample size limitations. Among the top models, the main factor that affected estimated kitten survival was whether recovery of dead panthers differed between kittens in the first 3 months of life and other panthers (low estimates of survival, about 0.33 ) or not (high estimates of survival, about 0.50 ). The modelaveraged estimate of annual kitten survival from the 3-month analysis was 0.404 (95\% CI: $0.169-0.693$ ). The uncertainty of this estimate was high due to 1) small sample sizes and uncertainty about the fates of individual kittens leading to large standard errors for estimates from individual models; 2) further increase of these standard errors by the variance inflation factor, to account for overdispersion; and 3 ) different models often producing very different estimates of kitten survival, and the unconditional confidence interval presented here incorporates that uncertainty.

Estimated annual survival rates of sub-adults and adults were fairly consistent among models and the model-averaged estimates were similar to those from the corresponding model in Benson et al. (2009; Table C3). The slightly lower estimate of sub-adult female survival may be in part due to a death of a female panther near her estimated $1^{\text {st }}$ birthday that was categorized as a sub-adult in the kitten analysis and as a kitten in the adult analysis. 
We selected two highly ranked models with differing estimates of kitten survival (models $1 \&$ 2 , Table $\mathrm{C} 2$ ) as base models for testing the effects of season on kitten survival. There was no evidence of an effect of season on kitten survival (Table C4).

\section{Table C1}

A priori models used for the analysis of A) recapture probability $(p), \mathrm{B})$ recovery probability $(r)$, and C) survival probability (age models only; $S$ ), using a 3-month time step. All combinations of $p, r$, and $S$ models in this table were run. We also tested for the effect of season (wet vs. dry) on $S$, using the top model(s) from this analysis. For all models, $p$ and $r$ were fixed at 1 for radio-collared panthers. We fixed $p$ at 0 for kittens younger than 6 months old and for kittens younger than 9 months old after November 2001 for all models. All models estimated non-kitten survival as the interaction of sex and age-class (sub-adult or adult); therefore, we only describe how kitten survival was modeled.

\begin{tabular}{|c|c|}
\hline A) Model for $p$ & Description \\
\hline 1. $p(\mathrm{k}: \mathrm{DO}, \mathrm{s} \& \mathrm{a})$ & $\begin{array}{l}\text { Recapture probability differs between kittens and older panthers, and between kittens } \\
\text { with dam origin of Florida and Texas. }\end{array}$ \\
\hline 2. $p(\mathrm{k}, \mathrm{s} \& \mathrm{a})$ & Recapture probability differs between kittens and older panthers. \\
\hline 3. $p()$. & Recapture probability is the same for all panthers. \\
\hline B) Model for $r$ & Description \\
\hline 4. $r(\mathrm{k}<3, \mathrm{k} \geq 3, \mathrm{~s} \& \mathrm{a})$ & $\begin{array}{l}\text { Recovery probability differs between kittens in their first three months, older kittens, and } \\
\text { non-kittens. }\end{array}$ \\
\hline 5. $r(\mathrm{k}<3, \geq 3)$ & Recovery probability differs between kittens in their first three months and older panthers. \\
\hline 6. $r()$. & Recovery probability the same for all panthers. \\
\hline C) Model for $S$ & Description \\
\hline 7. $S(\mathrm{k}<3,3 \leq \mathrm{k}<6,6 \leq \mathrm{k}<9, \mathrm{k} \geq 9)$ & Age effect (survival differs between each of 4 3-month age intervals) \\
\hline 8. $S(\mathrm{k}<6,6 \leq \mathrm{k}<9, \mathrm{k} \geq 9)$ & Age effect (survival same for first two age intervals) \\
\hline 9. $S(\mathrm{k}<3,3 \leq \mathrm{k}<9, \mathrm{k} \geq 9)$ & Age effect (survival same for second two age intervals) \\
\hline 10. $S(\mathrm{k}<6, \mathrm{k} \geq 6)$ & Age effect (survival same for first two age intervals, same for second two age intervals) \\
\hline 11. $S(\mathrm{k}<3, \mathrm{k} \geq 3)$ & Age effect (survival same for last three age intervals) \\
\hline 12. $S(\mathrm{AT})$ & Age trend (survival over the first 4 3-month intervals as a linear trend) \\
\hline 13. $S()$. & Survival same for all kittens \\
\hline
\end{tabular}

\section{Table C2}

Kitten survival models to examine the effects of age (3-month time step). For each model, we present the number of parameters $(\mathrm{K})$, the difference from the top model in second-order QuasiAkaike's Information Criterion $(\triangle \mathrm{QAIC})$, the model $\mathrm{QAIC}_{\mathrm{c}}$ weight, and the estimate of annual kitten survival with standard error. See Table $\mathrm{C} 1$ for descriptions of models. The base models selected are in bold.

\begin{tabular}{llllc}
\hline Model & K & $\Delta$ QAIC & Weight & $\begin{array}{c}\text { Annual Kitten Survival } \\
\text { Estimate (SE) }\end{array}$ \\
\hline $\mathbf{1 .} \boldsymbol{S}(\mathbf{k}<\mathbf{3}, \mathbf{k} \geq \mathbf{3}) \boldsymbol{p}(\mathbf{k}, \mathbf{s \& a}) \boldsymbol{r}(\mathbf{k}<\mathbf{3}, \geq \mathbf{3 3})$ & 10 & 0 & 0.170 & $0.323(0.090)$ \\
$\mathbf{2 .} \boldsymbol{S}(\mathbf{k}<\mathbf{3}, \mathbf{k} \geq \mathbf{3}) \boldsymbol{p}(\mathbf{k}, \mathbf{s \& a}) \boldsymbol{r}()$. & 9 & 1.170 & 0.095 & $0.508(0.136)$ \\
3. $S(\mathrm{k}<3,3 \leq \mathrm{k}<9, \mathrm{k} \geq 9) p(\mathrm{k}, \mathrm{s} \& \mathrm{a}) r(\mathrm{k}<3, \geq 3)$ & 11 & 1.361 & 0.086 & $0.326(0.091)$ \\
$4 . S(\mathrm{k}<3, \mathrm{k} \geq 3) p(\mathrm{k}, \mathrm{s} \& \mathrm{a}) r(\mathrm{k}<3, \mathrm{k} \geq 3, \mathrm{~s} \& \mathrm{a})$ & 11 & 1.518 & 0.079 & $0.326(0.092)$
\end{tabular}




\begin{tabular}{|c|c|c|c|c|}
\hline Model & $\mathbf{K}$ & $\Delta \mathrm{QAIC}_{\mathrm{c}}$ & Weight & $\begin{array}{c}\text { Annual Kitten Survival } \\
\text { Estimate (SE) }\end{array}$ \\
\hline 5. $S(\mathrm{AT}) p(\mathrm{k}, \mathrm{s} \& \mathrm{a}) r()$. & 9 & 1.914 & 0.065 & $0.484(0.133)$ \\
\hline 6. $S(\mathrm{k}<3, \mathrm{k} \geq 3) p(\mathrm{k}: \mathrm{DO}, \mathrm{s} \& \mathrm{a}) r(\mathrm{k}<3, \geq 3)$ & 11 & 1.991 & 0.063 & $0.326(0.093)$ \\
\hline 7. $S(\mathrm{k}<3,3 \leq \mathrm{k}<9, \mathrm{k} \geq 9) p(\mathrm{k}, \mathrm{s} \& \mathrm{a}) r()$. & 10 & 2.057 & 0.061 & $0.487(0.133)$ \\
\hline 8. $S(\mathrm{k}<3, \mathrm{k} \geq 3) p(\mathrm{k}: \mathrm{DO}, \mathrm{s} \& \mathrm{a}) r()$. & 10 & 2.935 & 0.039 & $0.517(0.136)$ \\
\hline 9. $S(\mathrm{k}<3,3 \leq \mathrm{k}<9, \mathrm{k} \geq 9) p(\mathrm{k}, \mathrm{s} \& \mathrm{a}) r(\mathrm{k}<3, \mathrm{k} \geq 3, \mathrm{~s} \& \mathrm{a})$ & 12 & 3.188 & 0.034 & $0.327(0.093)$ \\
\hline 10. $S(\mathrm{k}<3,3 \leq \mathrm{k}<9, \mathrm{k} \geq 9) p(\mathrm{k}: \mathrm{DO}, \mathrm{s} \& \mathrm{a}) r(\mathrm{k}<3, \geq 3)$ & 12 & 3.354 & 0.032 & $0.329(0.095)$ \\
\hline 11. $S(\mathrm{AT}) p(\mathrm{k}, \mathrm{s} \& \mathrm{a}) r(\mathrm{k}<3, \geq 3)$ & 10 & 3.454 & 0.030 & $0.399(0.137)$ \\
\hline 12. $S(\mathrm{k}<3, \mathrm{k} \geq 3) p(\mathrm{k}: \mathrm{DO}, \mathrm{s} \& \mathrm{a}) r(\mathrm{k}<3, \mathrm{k} \geq 3, \mathrm{~s} \& \mathrm{a})$ & 12 & 3.512 & 0.029 & $0.329(0.096)$ \\
\hline 13. $S(\mathrm{AT}) p(\mathrm{k}: \mathrm{DO}, \mathrm{s} \& \mathrm{a}) r()$. & 10 & 3.717 & 0.026 & $0.493(0.134)$ \\
\hline 14. $S(\mathrm{k}<3,3 \leq \mathrm{k}<9, \mathrm{k} \geq 9) p(\mathrm{k}: \mathrm{DO}, \mathrm{s} \& \mathrm{a}) r()$. & 11 & 3.863 & 0.025 & $0.496(0.134)$ \\
\hline 15. $S() p.(\mathrm{k}, \mathrm{s} \& \mathrm{a}) r(\mathrm{k}<3, \geq 3)$ & 9 & 4.42 & 0.019 & $0.770(0.137)$ \\
\hline 16. $S(\mathrm{AT}) p(\mathrm{k}, \mathrm{s} \& \mathrm{a}) r(\mathrm{k}<3, \mathrm{k} \geq 3, \mathrm{~s} \& \mathrm{a})$ & 11 & 4.58 & 0.018 & $0.355(0.111)$ \\
\hline 17. $S(\mathrm{k}<3,3 \leq \mathrm{k}<9, \mathrm{k} \geq 9) p(\mathrm{k}: \mathrm{DO}, \mathrm{s} \& \mathrm{a}) r(\mathrm{k}<3, \mathrm{k} \geq 3, \mathrm{~s} \& \mathrm{a})$ & 13 & 5.18 & 0.013 & $0.330(0.097)$ \\
\hline 18. $S(\mathrm{AT}) p(\mathrm{k}: \mathrm{DO}, \mathrm{s} \& \mathrm{a}) r(\mathrm{k}<3, \geq 3)$ & 11 & 5.36 & 0.012 & $0.411(0.148)$ \\
\hline 19. $S(\mathrm{k}<6, \mathrm{k} \geq 6) p(\mathrm{k}, \mathrm{s} \& \mathrm{a}) r()$. & 9 & 5.63 & 0.010 & $0.498(0.138)$ \\
\hline 20. $S(\mathrm{k}<6,6 \leq \mathrm{k}<9, \mathrm{k} \geq 9) p(\mathrm{k}, \mathrm{s} \& \mathrm{a}) r()$. & 10 & 5.67 & 0.010 & $0.481(0.133)$ \\
\hline 21. $S() p.(\mathrm{k}: \mathrm{DO}, \mathrm{s} \& \mathrm{a}) r(\mathrm{k}<3, \geq 3)$ & 10 & 5.98 & 0.009 & $0.775(0.135)$ \\
\hline 22. $S() p.(\mathrm{k}, \mathrm{s} \& \mathrm{a}) r(\mathrm{k}<3, \mathrm{k} \geq 3, \mathrm{~s} \& \mathrm{a})$ & 10 & 6.43 & 0.007 & $0.781(0.267)$ \\
\hline 23. $S(\mathrm{AT}) p(\mathrm{k}: \mathrm{DO}, \mathrm{s} \& \mathrm{a}) r(\mathrm{k}<3, \mathrm{k} \geq 3, \mathrm{~s} \& \mathrm{a})$ & 12 & 6.54 & 0.007 & $0.361(0.118)$ \\
\hline 24. $S() p.(\mathrm{k}, \mathrm{s} \& \mathrm{a}) r()$. & 8 & 7.12 & 0.005 & $0.590(0.129)$ \\
\hline 25. $S(\mathrm{k}<6,6 \leq \mathrm{k}<9, \mathrm{k} \geq 9) p(\mathrm{k}, \mathrm{s} \& \mathrm{a}) r(\mathrm{k}<3, \mathrm{k} \geq 3, \mathrm{~s} \& \mathrm{a})$ & 12 & 7.22 & 0.005 & $0.400(0.154)$ \\
\hline 26. $S(\mathrm{k}<6, \mathrm{k} \geq 6) p(\mathrm{k}: \mathrm{DO}, \mathrm{s} \& \mathrm{a}) r()$. & 10 & 7.40 & 0.004 & $0.507(0.139)$ \\
\hline 27. $S(\mathrm{k}<6,6 \leq \mathrm{k}<9, \mathrm{k} \geq 9) p(\mathrm{k}: \mathrm{DO}, \mathrm{s} \& \mathrm{a}) r()$. & 11 & 7.49 & 0.004 & $0.490(0.135)$ \\
\hline 28. $S(\mathrm{k}<6, \mathrm{k} \geq 6) p(\mathrm{k}, \mathrm{s} \& \mathrm{a}) r(\mathrm{k}<3, \mathrm{k} \geq 3, \mathrm{~s} \& \mathrm{a})$ & 11 & 7.74 & 0.004 & $0.404(0.163)$ \\
\hline 29. $S(\mathrm{k}<3, \mathrm{k} \geq 3) p() r.(\mathrm{k}<3, \geq 3)$ & 9 & 8.13 & 0.003 & $0.307(0.076)$ \\
\hline 30. $S() p.(\mathrm{k}: \mathrm{DO}, \mathrm{s} \& \mathrm{a}) r()$. & 9 & 8.79 & 0.002 & $0.595(0.128)$ \\
\hline 31. $S(\mathrm{k}<6,6 \leq \mathrm{k}<9, \mathrm{k} \geq 9) p(\mathrm{k}: \mathrm{DO}, \mathrm{s} \& \mathrm{a}) r(\mathrm{k}<3, \mathrm{k} \geq 3, \mathrm{~s} \& \mathrm{a})$ & 13 & 9.13 & 0.002 & $0.414(0.172)$ \\
\hline 32. $S(\mathrm{k}<3,3 \leq \mathrm{k}<9, \mathrm{k} \geq 9) p() r.(\mathrm{k}<3, \geq 3)$ & 10 & 9.62 & 0.001 & $0.308(0.077)$ \\
\hline 33. $S(\mathrm{k}<6, \mathrm{k} \geq 6) p(\mathrm{k}: \mathrm{DO}, \mathrm{s} \& \mathrm{a}) r(\mathrm{k}<3, \mathrm{k} \geq 3, \mathrm{~s} \& \mathrm{a})$ & 12 & 9.62 & 0.001 & $0.422(0.189)$ \\
\hline 34. $S(\mathrm{k}<3, \mathrm{k} \geq 3) p() r.()$. & 8 & 9.91 & 0.001 & $0.437(0.118)$ \\
\hline 35. $S(\mathrm{k}<3, \mathrm{k} \geq 3) p() r.(\mathrm{k}<3, \mathrm{k} \geq 3, \mathrm{~s} \& \mathrm{a})$ & 10 & 9.95 & 0.001 & $0.308(0.077)$ \\
\hline 36. $S(\mathrm{AT}) p() r.()$. & 8 & 10.77 & 0.001 & $0.420(0.113)$ \\
\hline 37. $S(\mathrm{k}<3,3 \leq \mathrm{k}<9, \mathrm{k} \geq 9) p() r.()$. & 9 & 10.98 & 0.001 & $0.423(0.113)$ \\
\hline 38. $S(\mathrm{k}<3,3 \leq \mathrm{k}<9, \mathrm{k} \geq 9) p() r.(\mathrm{k}<3, \mathrm{k} \geq 3, \mathrm{~s} \& \mathrm{a})$ & 11 & 11.57 & 0.001 & $0.308(0.077)$ \\
\hline 39. $S(\mathrm{AT}) p() r.(\mathrm{k}<3, \geq 3)$ & 9 & 11.97 & 0.000 & $0.355(0.101)$ \\
\hline 40. $S(\mathrm{AT}) p() r.(\mathrm{k}<3, \mathrm{k} \geq 3, \mathrm{~s} \& \mathrm{a})$ & 10 & 12.59 & 0.000 & $0.326(0.086)$ \\
\hline 41. $S(\mathrm{k}<6, \mathrm{k} \geq 6) p() r.()$. & 8 & 14.13 & 0.000 & $0.428(0.117)$ \\
\hline 42. $S() p.() r.(\mathrm{k}<3, \geq 3)$ & 8 & 14.18 & 0.000 & $0.640(0.184)$ \\
\hline 43. $S(\mathrm{k}<6,6 \leq \mathrm{k}<9, \mathrm{k} \geq 9) p() r.()$. & 9 & 14.39 & 0.000 & $0.417(0.112)$ \\
\hline 44. $S() p.() r.(\mathrm{k}<3, \mathrm{k} \geq 3, \mathrm{~s} \& \mathrm{a})$ & 9 & 14.57 & 0.000 & $0.426(0.144)$ \\
\hline 45. $S(\mathrm{k}<6,6 \leq \mathrm{k}<9, \mathrm{k} \geq 9) p() r.(\mathrm{k}<3, \mathrm{k} \geq 3, \mathrm{~s} \& \mathrm{a})$ & 11 & 14.99 & 0.000 & $0.350(0.099)$ \\
\hline 46. $S() p.() r.()$. & 7 & 15.09 & 0.000 & $0.487(0.125)$ \\
\hline
\end{tabular}

Biol Conserv. Author manuscript; available in PMC 2011 November 1. 


\begin{tabular}{llllc}
\hline Model & K & $\Delta \mathbf{Q A I C}_{\mathbf{c}}$ & Weight & $\begin{array}{c}\text { Annual Kitten Survival } \\
\text { Estimate (SE) }\end{array}$ \\
\hline 47. $S(\mathrm{k}<6, \mathrm{k} \geq 6) p() r.(\mathrm{k}<3, \mathrm{k} \geq 3, \mathrm{~s} \& \mathrm{a})$ & 10 & 15.21 & 0.000 & $0.350(0.101)$ \\
48. $S(\mathrm{k}<6, \mathrm{k} \geq 6) p() r.(\mathrm{k}<3, \geq 3)$ & 9 & 15.87 & 0.000 & $0.491(0.218)$ \\
49. $S(\mathrm{k}<6,6 \leq \mathrm{k}<9, \mathrm{k} \geq 9) p() r.(\mathrm{k}<3, \geq 3)$ & 10 & 16.01 & 0.000 & $0.488(0.211)$ \\
\hline
\end{tabular}

\section{Table C3}

Estimates of annual sub-adult and adult survival from the 3-month kitten survival analysis and the adult analysis of Benson et al. (2009). Sub-adult is defined as ages 1-2.5 for females and 1-3.5 for males; adult is defined as ages 2.5 and up for females and 3.5 and up for males. The results from the kitten analysis are the model-averaged survivals from all models in the 3month analysis; the results from the adult analysis are from the Sex * Age1 model (Benson et al. 2009).

\begin{tabular}{llll}
\hline & & \multicolumn{2}{c}{ Annual Survival Estimates (SE) } \\
Sex & Age Class & Kitten Analysis & Adult Analysis \\
\hline Female & Sub-Adult & $0.929(0.051)$ & $0.954(0.032)$ \\
Female & Adult & $0.858(0.03)$ & $0.852(0.023)$ \\
Male & Sub-Adult & $0.723(0.066)$ & $0.712(0.05)$ \\
Male & Adult & $0.774(0.049)$ & $0.782(0.035)$ \\
\hline
\end{tabular}

Table C4

Model comparison table for examining the effects of season on kitten survival. For each model, we present the number of parameters $(\mathrm{K})$, the difference from the top model in second-order Quasi-Akaike's Information Criterion $\left(\Delta \mathrm{QAIC}_{\mathrm{c}}\right)$, the model $\mathrm{QAIC}_{\mathrm{c}}$ weight, and the estimate of seasonal kitten survival with standard error. The same recapture model $(p(\mathrm{k}, \mathrm{s} \& \mathrm{a}))$ was used in all models. See Table C1 for descriptions of models.

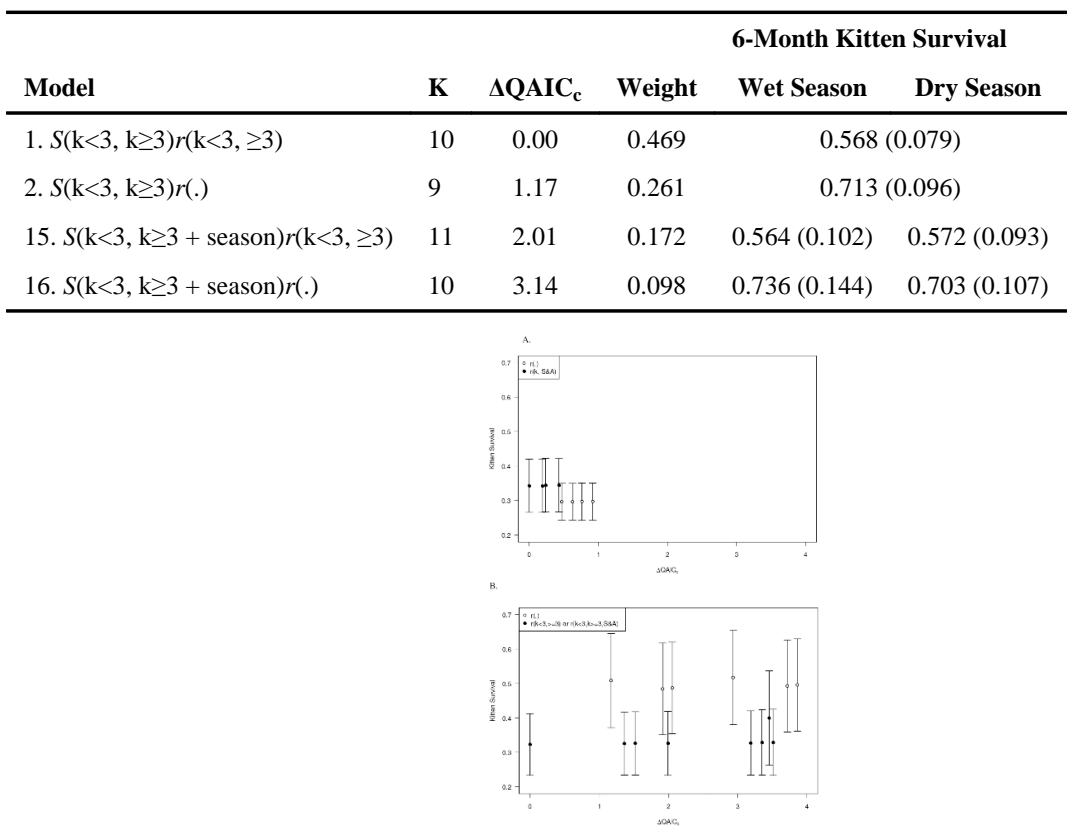

Biol Conserv. Author manuscript; available in PMC 2011 November 1. 


\section{Figure C1.}

Individual model estimates of annual kitten survival A) from the 1-year time step analysis and B) from the 3-month time step analysis. All models are shown in A, whereas only top models (the difference from the top model in second-order Quasi-Akaike's Information Criterion or $\left.\Delta \mathrm{QAIC}_{\mathrm{c}}<4\right)$ are plotted in $\mathrm{B}$. Models are aligned by their $\Delta \mathrm{QAIC} \mathrm{c}_{\mathrm{c}}$ value on the $\mathrm{x}$-axis. Error bars represent standard errors (adjusted by the variance inflation factor).

\section{Appendix D}

\section{Including another Base Model}

\section{Methods}

To examine the effects of base model uncertainty on covariate testing, we ran all covariates with the highest ranked model from Table 2 that had a different estimate of kitten survival than the base model (this was model 5). This model (hereafter called base2) modeled survival identically to the base model but estimated one recovery rate for all panthers instead of dividing it between kittens and older panthers. All covariate analyses were performed the same way as in the main text. We report full model average estimates based on all models run with both base models.

\section{Results}

All covariate models using base 2 could estimate all parameters. There was still no evidence that sex or litter size affected kitten survival (Table D1). There was still considerable evidence that ancestry influenced kitten survival; the 7 most parsimonious models all included ancestry effects on kitten survival (models 1-7, Table D2A). The top 2 models indicated that survival of kittens differed substantially between two ancestry categories: 1) canonical and backcrossed to canonical kittens and 2) $\mathrm{F}_{1}$, backcrossed to Texas, and backcrossed to Everglades kittens (Table D2A). Full model-averaged kitten survival was lowest for canonical kittens and highest for $\mathrm{F}_{1}$ kittens (Figure D1A), and were slightly lower for all ancestry classes than model averages from the base model alone (Figure 1A).

The most parsimonious model testing for the effect of heterozygosity on survival indicated that survival of panthers of all ages (including survival of kittens) was positively affected by average heterozygosity (Table D2B, model 1). Full model-averaged estimated kitten survival increased with heterozygosity (Figure D1B).

The evidence for the effect of abundance index on kitten survival was even stronger using base2 (Table D2C). Full model-averaged estimated kitten survival declined with abundance index (Figure D2). We estimated temporal standard deviation of kitten survival $(\sigma)$ at 0.199 $(95 \%$ credible interval $=0.011-0.380)$ and $0.077(95 \%$ credible interval $=0.003-0.234)$ using models without and with abundance index, respectively.

The most parsimonious model testing for the effect of simple ancestry on survival indicated that survival of panthers of all ages (including survival of kittens) was higher for $F_{1}$ admixed (Table D3, model 1). Full model-averaged estimated kitten survivals increased from canonical to other admixed to $F_{1}$ admixed (Figure D3), and were slightly lower for all ancestry classes than model averages from the base model alone (Figure A1).

Interestingly, unconditional standard errors estimated for the full model set tended to be lower than those estimated for the base model set alone, even when the full model-averaged estimate was closer to 0.5 . 


\section{Table D1}

Model selection table for A) sex effect on kitten survival and B) litter size effect on kitten survival. For each model, we present the number of parameters $(\mathrm{K})$, the difference from the top model in Akaike's Information Criterion adjusted for overdispersion and small sample size $\left(\triangle \mathrm{QAIC}_{\mathrm{c}}\right)$, the model QAIC $\mathrm{c}_{\mathrm{c}}$ weight, and the estimates of annual kitten survival with standard error (for both sexes and the highest and lowest litter sizes). The $\mathrm{QAIC}_{\mathrm{c}}$ values of the top models are 857.23 and 845.66, respectively (compare to $\mathrm{QAIC}_{\mathrm{c}}$ values for the base models run with the same datasets of 856.76 and 845.64, respectively). See Table 1 for descriptions of the covariate models and Table 2 (model 5) for the base 2 model. The litter size analysis was performed on a subset of the data (excluding kittens from litters of unknown size). All models estimate constant recapture and recovery rates $(p() r.()$.$) .$

\begin{tabular}{lccccc}
\hline $\begin{array}{l}\text { A. Sex models } \\
\text { Survival Model }\end{array}$ & K & SQAIC $_{\mathbf{c}}$ & Weight & Female & Male \\
\hline $\begin{array}{lcccc}\text { 1. base2 } \\
\text { 2. base2 + k:sex }\end{array}$ & 8 & 1.94 & 0.275 & $0.311(0.068)$ & $0.282(0.065)$ \\
\hline B. Litter size models & & & & Annual Kitten Survival Estimate (SE) \\
Survival Model & $\mathrm{K}$ & $\Delta$ QAIC $_{\mathrm{c}}$ & Weight & 1 kitten & 4 kittens \\
\hline 1. base2 & 7 & 0.00 & 0.735 & 0.725 & $0.280(0.050)$ \\
2. base2 + k:LS & 8 & 2.04 & 0.265 & $0.279(0.109)$ & $0.280(0.081)$ \\
\hline
\end{tabular}

\section{Table D2}

Model selection table for A) ancestry effects on kitten and older survival, B) heterozygosity effects on kitten and older survival, and C) abundance index effects on kitten survival. These analyses were performed on subsets of the data (excluding panthers before 1995 for all analyses and panthers of unknown ancestry for A, and panthers before their heterozygosity was successfully sampled for B). For each model, we present the number of parameters (K), the difference from the top model in Akaike's Information Criterion adjusted for overdispersion and small sample size $(\triangle \mathrm{QAIC})$, and the model $\mathrm{QAIC} \mathrm{C}_{\mathrm{c}}$ weight. The $\mathrm{QAIC}_{\mathrm{c}}$ values of the top models are 623.98, 577.80, and 716.22, respectively (compare to $\mathrm{QAIC}_{\mathrm{c}}$ values for the top models of Table 3 of 624.41, 577.37, and 716.46, respectively). See Table 1 for descriptions of the covariate models and Table 2 (model 5) for the base 2 model. All models estimate constant recapture and recovery rates $(p() r.()$.$) .$

\begin{tabular}{lccc}
\hline $\begin{array}{l}\text { A. Ancestry models } \\
\text { Survival Model }\end{array}$ & K & $\Delta$ QAIC $_{\mathbf{c}}$ & Weight \\
\hline 1. base2 + k:GenAnc2 + s\&a:GenAnc6 & 9 & 0.00 & 0.232 \\
2. base2 + GenAnc2 & 8 & 1.18 & 0.128 \\
3. base2 + GenAnc6 & 8 & 1.35 & 0.118 \\
4. base2 + GenAnc4 & 9 & 1.83 & 0.093 \\
5. base2 + k:GenAnc3 + s\&a:GenAnc6 & 9 & 2.07 & 0.082 \\
6. base2 + k:GenAnc6 + s\&a:GenAnc6 & 9 & 3.20 & 0.047 \\
7. base2 + GenAnc3 & 8 & 3.21 & 0.047 \\
8. base2 + s\&a:GenAnc6 & 8 & 3.23 & 0.046 \\
9. base2 + k:GenAnc1 + s\&a:GenAnc6 & 9 & 3.71 & 0.036
\end{tabular}




\begin{tabular}{|c|c|c|c|}
\hline \multicolumn{4}{|l|}{ A. Ancestry models } \\
\hline Survival Model & $\mathbf{K}$ & $\Delta \mathrm{QAIC}_{\mathrm{c}}$ & Weigh \\
\hline 10. base2 + k:GenAnc5 + s\&a:GenAnc6 & 10 & 3.84 & 0.034 \\
\hline 11. base2 + k:GenAnc2 & 8 & 3.85 & 0.034 \\
\hline 12. base $2+\mathrm{k}:$ GenAnc $4+\mathrm{s} \& \mathrm{a}:$ GenAnc6 & 10 & 4.29 & 0.027 \\
\hline 13. base $2+$ GenAnc5 & 9 & 4.69 & 0.022 \\
\hline 14. base $2+$ GenAnc 1 & 8 & 5.55 & 0.014 \\
\hline 15. base2 + k:GenAnc3 & 8 & 5.94 & 0.012 \\
\hline 16. base2 + k:GenAnc6 & 8 & 6.44 & 0.009 \\
\hline 17. base2 + k:GenAnc4 & 9 & 7.53 & 0.005 \\
\hline 18. base 2 & 7 & 7.54 & 0.005 \\
\hline 19. base2 + k:GenAnc5 & 9 & 7.72 & 0.005 \\
\hline 20. base $2+\mathrm{k}:$ GenAnc 1 & 8 & 7.93 & 0.004 \\
\hline \multicolumn{4}{|l|}{ B. Heterozygosity models } \\
\hline Survival Model & $\mathrm{K}$ & $\triangle \mathrm{QAICc}$ & Weigh \\
\hline 1. base $2+$ Het & 8 & 0.00 & 0.320 \\
\hline 2. base $2+\mathrm{s} \& \mathrm{a}: \mathrm{Het}$ & 8 & 0.53 & 0.245 \\
\hline 3. base 2 & 7 & 0.78 & 0.216 \\
\hline 4. base $2+\mathrm{k}: \mathrm{Het}+\mathrm{s} \& \mathrm{a}: \mathrm{Het}$ & 9 & 2.07 & 0.114 \\
\hline 5. base $2+\mathrm{k}: \mathrm{Het}$ & 8 & 2.22 & 0.105 \\
\hline \multicolumn{4}{|l|}{ C. Abundance index models } \\
\hline Survival Model & $\mathrm{K}$ & $\triangle \mathrm{QAICc}$ & Weigh \\
\hline 1. base2 + k:Abundance & 8 & 0.00 & 0.992 \\
\hline 2. base2 & 7 & 9.65 & 0.008 \\
\hline
\end{tabular}

\section{Table D3}

Model selection table for three category ancestry effects on kitten and older survival. These analyses were performed on subsets of the data (excluding panthers before 1995 and panthers of unknown ancestry). For each model, we present the number of parameters (K), the difference from the top model in Akaike's Information Criterion adjusted for overdispersion and small sample size $(\triangle \mathrm{QAIC} C)$, and the model $\mathrm{QAIC}_{\mathrm{c}}$ weight. The $\mathrm{QAIC}_{\mathrm{c}}$ value of the top model is 716.21 (compare to $\mathrm{QAIC}_{\mathrm{c}}$ value for the top model of Table A2 of 715.74). See Table A1 for descriptions of the covariate models and Table 2 (model 5) for the base 2 model. All models estimate constant recapture and recovery rates $(p() r.()$.$) .$

\begin{tabular}{lccc}
\hline Survival Model & K & $\Delta$ QAICc & Weight \\
\hline 1. base2 + Ancest2 & 8 & 0.00 & 0.321 \\
2. base2 + Ancest1 & 9 & 1.04 & 0.191 \\
3. base2 + s\&a:Ancest2 & 8 & 1.68 & 0.138 \\
4. base2 + k:Ancest2 + s\&a:Ancest2 & 9 & 1.77 & 0.133 \\
5. base2 + k:Ancest3 + s\&a:Ancest2 & 9 & 2.68 & 0.084 \\
6. base2 + k:Ancest1 + s\&a:Ancest2 & 10 & 3.19 & 0.065
\end{tabular}




\begin{tabular}{lccc}
\hline Survival Model & K & $\Delta$ QAICc & Weight \\
\hline 7. base2 + k:Ancest2 & 8 & 5.50 & 0.020 \\
8. base2 + Ancest3 & 8 & 5.74 & 0.018 \\
9. base2 & 7 & 6.58 & 0.012 \\
10. base2 + k:Ancest1 & 9 & 6.92 & 0.010 \\
11. base2 + k:Ancest3 & 8 & 7.50 & 0.008 \\
\hline
\end{tabular}

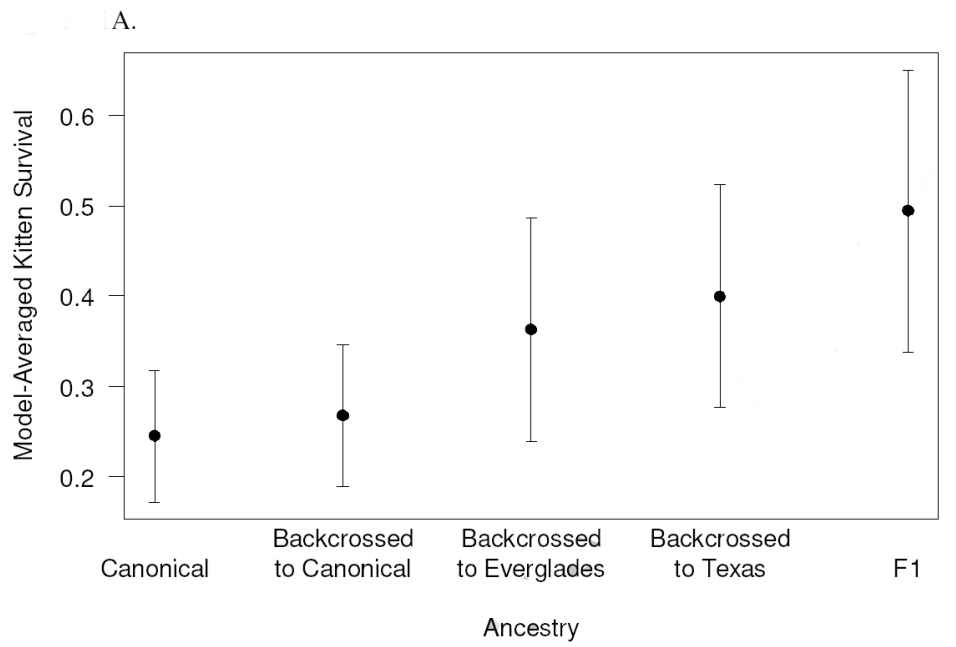

B.



Figure D1.

The effect of genetic variables on model-averaged kitten survival estimates, including two different base models (base and base2). A) Annual survival plotted against ancestry category. B) Annual survival plotted against heterozygosity. Error bars represent unconditional estimated standard errors. 




Figure D2.

The effect of a panther abundance index on model-averaged kitten survival estimates, including two different base models (base and base2). Error bars represent unconditional estimated standard errors.



Figure D3.

Model-averaged estimates of annual survival of Florida panther kittens based on 3 ancestry categories, including two different base models. Error bars represent unconditional estimated standard errors.

\section{Appendix Literature Cited}

Benson, JF.; Hostetler, JA.; Onorato, DP.; Johnson, WE.; Roelke, M.; O’Brien, SJ.; Jansen, D.; Oli, MK. Survival and cause-specific mortality of sub-adult and adult Florida panthers. In: Hostetler, JA.; Onorato, DP.; Oli, MK., editors. Population ecology of the Florida panther. The Florida Fish and Wildlife Conservation Commission and The US Fish and Wildlife Service; 2009. p. 10-61.

Bishop CJ, White GC, Lukacs PM. Evaluating dependence among mule deer siblings in fetal and neonatal survival analyses. Journal of Wildlife Management 2008;72:1085-1093.

Burnham, KP.; Anderson, DR. Model selection and multimodel inference. 2. Springer; New York: 2002.

Maehr DS, Land ED, Roof JC, McCown JW. Day beds, natal dens, and activity of Florida panthers. Annual Conference of Southeast Fish and Wildlife Agencies 1990:310-318. 


\section{Acknowledgments}

We thank D. Land, M. Cunningham, Roy McBride, M. Lotz, D. Shindle, M. Criffield, S. Schulze, D. Giardina, A. Johnson, L. Oberhofer, M. Alvarado, H. Fitting and Rocky, Rowdy, and C. McBride and others for assistance with fieldwork. We also thank B. Bolker, J. Hines, G. White, J. Laake, and E. Cooch for technical and statistical advice, and D. Land, T. O'Meara, J. Gore, P. Beier, and two anonymous reviewers for reviewing earlier versions of this manuscript. This work was funded through the Florida Panther Research and Management Trust Fund, National Park Service, University of Florida, and grant Agreement No: 401816G091 from the United States Fish and Wildlife Service. The views and conclusions presented herein are those of the authors and do not necessarily reflect the views and conclusions of the federal government.

\section{Literature Cited}

Barone MA, Roelke ME, Howard J, Brown JL, Anderson AE, Wildt DE. Reproductive characteristics of male Florida panthers - comparative studies from Florida, Texas, Colorado, Latin America, and North American zoos. Journal of Mammalogy 1994;75:150-162.

Beier, P.; Vaughan, MR.; Conroy, MJ.; Quigley, H. An analysis of scientific literature related to the Florida panther. Florida Fish and Wildlife Conservation Commission; Tallahassee: 2003.

Beier P, Vaughan MR, Conroy MJ, Quigley H. Evaluating scientific inferences about the Florida panther. Journal of Wildlife Management 2006;70:236-245.

Belden RC, Frankenberger WB, McBride RT, Schwikert ST. Panther habitat use in southern Florida. Journal of Wildlife Management 1988;52:660-663.

Benson, JF.; Hostetler, JA.; Onorato, DP.; Johnson, WE.; Roelke, M.; O’Brien, SJ.; Jansen, D.; Oli, MK. Survival and cause-specific mortality of sub-adult and adult Florida panthers. In: Hostetler, JA.; Onorato, DP.; Oli, MK., editors. Population ecology of the Florida panther. The Florida Fish and Wildlife Conservation Commission and The US Fish and Wildlife Service; 2009. p. 10-61.

Bishop CJ, White GC, Lukacs PM. Evaluating dependence among mule deer siblings in fetal and neonatal survival analyses. Journal of Wildlife Management 2008;72:1085-1093.

Brito D. Genetic consequences of population subdivision: the marsupial Micoureus paraguayanus (Mammalia: Didelphimorphia) as a case study. Zoologia 2009;26:684-693.

Burnham, KP. A theory for combined analysis of ring recovery and recapture data. In: Lebreton, J-D.; North, PM., editors. Marked individuals in the study of bird population. Birkhäuser Verlag; Boston, MA: 1993. p. 199-213.

Burnham, KP.; Anderson, DR. Model selection and multimodel inference. 2. Springer; New York: 2002.

Caswell, H. Matrix population models. Second. Sinauer Associates; Sunderland, MA: 2001.

Caughley, G.; Gunn, A. Conservation biology in theory and practice. Blackwell Science; Cambridge, MA, USA: 1996.

Creel S. Recovery of the Florida panther - genetic rescue, demographic rescue, or both? Response to Pimm et al. (2006). Animal Conservation 2006;9:125-126.

Crnokrak P, Roff DA. Inbreeding depression in the wild. Heredity 1999;83:260-270. [PubMed: 10504423]

Crow JF. Alternative hypotheses of hybrid vigor. Genetics 1948;33:477-487.

Davis JB, Cox RR, Kaminski RM, Leopold BD. Survival of wood duck ducklings and broods in Mississippi and Alabama. Journal of Wildlife Management 2007;71:507-517.

Driscoll CA, Menotti-Raymond M, Nelson G, Goldstein D, O’Brien SJ. Genomic microsatellites as evolutionary chronometers: A test in wild cats. Genome Research 2002;12:414-423. [PubMed: 11875029]

Edmands S. Between a rock and a hard place: evaluating the relative risk of inbreeding and outbreeding for conservation and management. Molecular Ecology 2007;16:463-475. [PubMed: 17257106]

Frankham, R.; Ballou, JD.; Briscoe, DA. Introduction to conservation genetics. Cambridge University Press; Cambridge, UK: 2002.

Franklin, IR. Evolutionary change in small populations. In: Soule, ME.; Wilcox, BA., editors. Conservation Biology: An Evolutionary-Ecological Perspective. Sinauer Associates; Sunderland, Massachusetts, USA: 1980. p. 135-149. 
Fujiwara M, Caswell H. Demography of the endangered North Atlantic right whale. Nature 2001;414:537-541. [PubMed: 11734852]

Garrison EP, McCown JW, Oli MK. Reproductive ecology and cub survival of Florida black bears. Journal of Wildlife Management 2007;71:720-727.

Gelman, A. Inference and monitoring convergence. In: Gilks, WR.; Richardson, S.; Spiegelhalter, DJ., editors. Markov Chain Monte Carlo in Practice. Chapman and Hall/CRC; Boca Raton, Florida, USA: 1996. p. 131-143.

Gross L. Why not the best? How science failed the Florida panther. PloS Biology 2005;3:1525-1531.

Heppell SS, Caswell H, Crowder LB. Life histories and elasticity patterns: Perturbation analysis for species with minimal demographic data. Ecology 2000;81:654-665.

Heschel MS, Paige KN. Inbreeding depression, environmental-stress, and population-size variation in scarlet-gilia (Ipomopsis aggregata). Conservation Biology 1995;9:126-133.

Kautz R, Kawula R, Hoctor T, Comiskey J, Jansen D, Jennings D, Kasbohm J, Mazzotti F, McBride R, Richardson L, Root K. How much is enough? Landscape-scale conservation for the Florida panther. Biological Conservation 2006;130:118-133.

Laake, J.; Rexstad, E. Cooch, E.; White, GC., editors. RMark - an alternative approach to building linear models in MARK; Program MARK - 'a gentle introduction'. 92010. p. C1C108.http://www.phidot.org/software/mark/docs/book/

Lambert CMS, Wielgus RB, Robinson HS, Katnik DD, Cruickshank HS, Clarke R, Almack J. Cougar population dynamics and viability in the Pacific Northwest. Journal of Wildlife Management 2006;70:246-254.

Land ED, Garman DR, Holt GA. Monitoring female Florida panthers via cellular telephone. Wildlife Society Bulletin 1998;26:29-31.

Land ED, Shindle DB, Kawula RJ, Benson JF, Lotz MA, Onorato DP. Florida panther habitat selection analysis of concurrent GPS and VHF telemetry data. Journal of Wildlife Management 2008;72:633639.

Laundré JW, Hernández L, Clark SG. Numerical and demographic responses of pumas to changes in prey abundance: testing current predictions. Journal of Wildlife Management 2007;71:345-355.

Logan, KA.; Sweanor, LL. Desert puma: evolutionary ecology and conservation of an enduring carnivore. Island Press; Washington, DC: 2001.

Loison A, Sæther B-E, Jerstad K, Røstad OW. Disentangling the sources of variation in the survival of the European dipper. Journal of Applied Statistics 2002;29:289-304.

Lukacs PM, White GC, Watkins BE, Kahn RH, Banulis BA, Finley DJ, Holland AA, Martens JA, Vayhinger J. Separating components of variation in survival of mule deer in Colorado. Journal of Wildlife Management 2009;73:817-826.

Madsen T, Shine R, Olsson M, Wittzell H. Restoration of an inbred adder population. Nature 1999;402:34-35.

Maehr, DS. Florida panther. In: Humphrey, SR., editor. Rare and endangered biota of Florida, volume I. mammals. University Press of Florida; Gainesville, FL: 1992. p. 176-189.

Maehr DS, Caddick GB. Demographics and genetic introgression in the Florida panther. Conservation Biology 1995;9:1295-1298.

Maehr DS, Crowley P, Cox JJ, Lacki MJ, Larkin JL, Hoctor TS, Harris LD, Hall PM. Of cats and Haruspices: genetic intervention in the Florida panther. Response to Pimm et al. (2006). Animal Conservation 2006;9:127-132.

Maehr, DS.; Lacy, RC.; Land, ED.; Bass, OL.; Hoctor, T. Evolution of population viability assessments for the Florida panther: a multiperspective approach. In: Beissinger, SR.; McCullough, DR., editors. Population viability analysis. University of Chicago Press; Chicago: 2002. p. 284-311.

Maehr DS, Land ED, Roof JC, McCown JW. Day beds, natal dens, and activity of Florida panthers. Annual Conference of Southeast Fish and Wildlife Agencies 1990:310-318.

McBride RT, McBride RT, McBride RM, McBride CE. Counting pumas by categorizing physical evidence. Southeastern Naturalist 2008;7:381-400. 
Menotti-Raymond M, David VA, Lyons LA, Schäffer AA, Tomlin JF, Hutton MK, O'Brien SJ. A genetic linkage map of microsatellites in the domestic cat (Felis catus). Genomics 1999;57:9-23. [PubMed: 10191079]

Menotti-Raymond M, David VA, Stephens JC, Lyons LA, O’Brien SJ. Genetic individualization of domestic cats using feline STR loci for forensic applications. Journal of Forensic Science 1997;42:1039-1051.

Minch, E.; Ruiz-Linares, A.; Goldstein, DB. MICROSAT. 1995. http://hpgl.stanford.edu/projects/microsat/

Morris, WF.; Doak, DF. Quantitative conservation biology: theory and practice of population viability analysis. Sinauer Associates; Sunderland, MA: 2002.

Newton I. The recent declines of farmland bird populations in Britain: an appraisal of causal factors and conservation actions. Ibis 2004;146:579-600.

Nilsson T. Integrating effects of hunting policy, catastrophic events, and inbreeding depression, in PVA simulation: the Scandinavian wolf population as an example. Biological Conservation 2004;115:227-239.

O’Brien SJ, Roelke ME, Yuhki N, Richards KW, Johnson WE, Franklin WL, Anderson AE, Bass OL, Belden RC, Martenson JS. Genetic introgression within the Florida panther Felis concolor coryi. National Geographic Research 1990;6:485-494.

Oli MK, Dobson FS. The relative importance of life-history variables to population growth rate in mammals: Cole's prediction revisited. American Naturalist 2003;161:422-440.

Onorato, DP.; Belden, RC.; Cunningham, MW.; Land, ED.; McBride, RT.; Roelke, ME. Long-term research on the Florida panther (Puma concolor coryi): historical findings and future obstacles to population persistence. In: MacDonald, DW.; Loveridge, AJ., editors. Biology and conservation of wild felids. Oxford University Press; Oxford, UK: 2010. p. 452-469.

Ozgul A, Armitage KB, Blumstein DT, Oli MK. Spatiotemporal variation in survival rates: Implications for population dynamics of yellow-bellied marmots. Ecology 2006;87:1027-1037. [PubMed: 16676546]

Packer C, Kosmala M, Cooley HS, Brink H, Pintea L, Garshelis D, Purchase G, Strauss M, Swanson A, Balme G, Hunter L, Nowell K. Sport hunting, predator control and conservation of large carnivores. PLoS One 2009;4:e5941. [PubMed: 19536277]

Pimm SL, Dollar L, Bass OL. The genetic rescue of the Florida panther. Animal Conservation 2006;9:115-122.

Pollock KH. Capture-recapture models allowing for age-dependent survival and capture rates. Biometrics 1981;37:521-529.

Pritchard JK, Stephens M, Donnelly P. Inference of population structure using multilocus genotype data. Genetics 2000;155:945-959. [PubMed: 10835412]

R Development Core Team. R: A language and environment for statistical computing. R Foundation for Statistical Computing; Vienna, Austria: 2010.

Ralls, K.; Ballou, J. Extinction: lessons from zoos. In: Schonewald-Cox, CM.; Chambers, SM.; MacBryde, B.; Thomas, WL., editors. Genetics and Conservation: A Reference for Managing Wild Animal and Plant Populations. Benjamin/Cummings; Menlo Park, California: 1983. p. 164-184.

Robinson HS, Wielgus RB, Cooley HS, Cooley SW. Sink populations in carnivore management: Cougar demography and immigration in a hunted population. Ecological Applications 2008;18:1028-1037. [PubMed: 18536260]

Roelke ME, Martenson JS, Obrien SJ. The consequences of demographic reduction and genetic depletion in the endangered Florida panther. Current Biology 1993;3:340-350. [PubMed: 15335727]

Root, KV. Florida panther (Puma concolor coryi): using models to guide recovery efforts. In: Akçakaya, HR.; Burgman, MA.; Kindvall, O.; Wood, CC.; Sjogren-Gulve, P.; Hatfield, JS.; McCarthy, MA., editors. Species Conservation and Management: Case Studies. Oxford University Press, New York; New York, USA: 2004. p. 491-504.

Seal, US. A plan for genetic restoration and management of the Florida panther (Felis concolor coryi). Conservation Breeding Specialist Group, Apple Valley; Minnesota, USA: 1994. 
Shields, WM. The natural and unnatural history of inbreeding and outbreeding. In: Thornhill, NW., editor. The natural history of inbreeding and outbreeding: theoretical and empirical perspectives. The University of Chicago Press; Chicago, Illinois, USA: 1993. p. 143-169.

Stahl JT, Oli MK. Relative importance of avian life-history variables to population growth rate. Ecological Modelling 2006;198:23-39.

Tinker MT, Doak DF, Estes JA, Hatfield BB, Hatfield BB, Staedler MM, Bodkin JL. Incorporating diverse data and realistic complexity into demographic estimation procedures for sea otters. Ecological Applications 2006;16:2293-2312. [PubMed: 17205905]

Vrijenhoek, RC. Genetic diversity and fitness in small populations. In: Loeschcke, V.; Tomiuk, J.; Jain, SK., editors. Conservation genetics. Birkhäuser Verlag; Boston: 1994. p. 37-53.

White, GC.; Burnam, KP.; Barker, RJ. Evaluation of a Bayesian MCMC random effects inference methodology for capture-mark-recapture data. In: Thomson, DL.; Cooch, EG.; Conroy, MJ., editors. Modeling demographic processes in marked populations. Springer; New York, NY: 2009. p. 1119-1127.

White GC, Burnham KP. Program MARK: survival estimation from populations of marked animals. Bird Study 1999;46:S120-S139.

Williams, BK.; Nichols, JD.; Conroy, MJ. Analysis and management of animal populations. Academic Press; San Diego, CA, USA: 2002. 

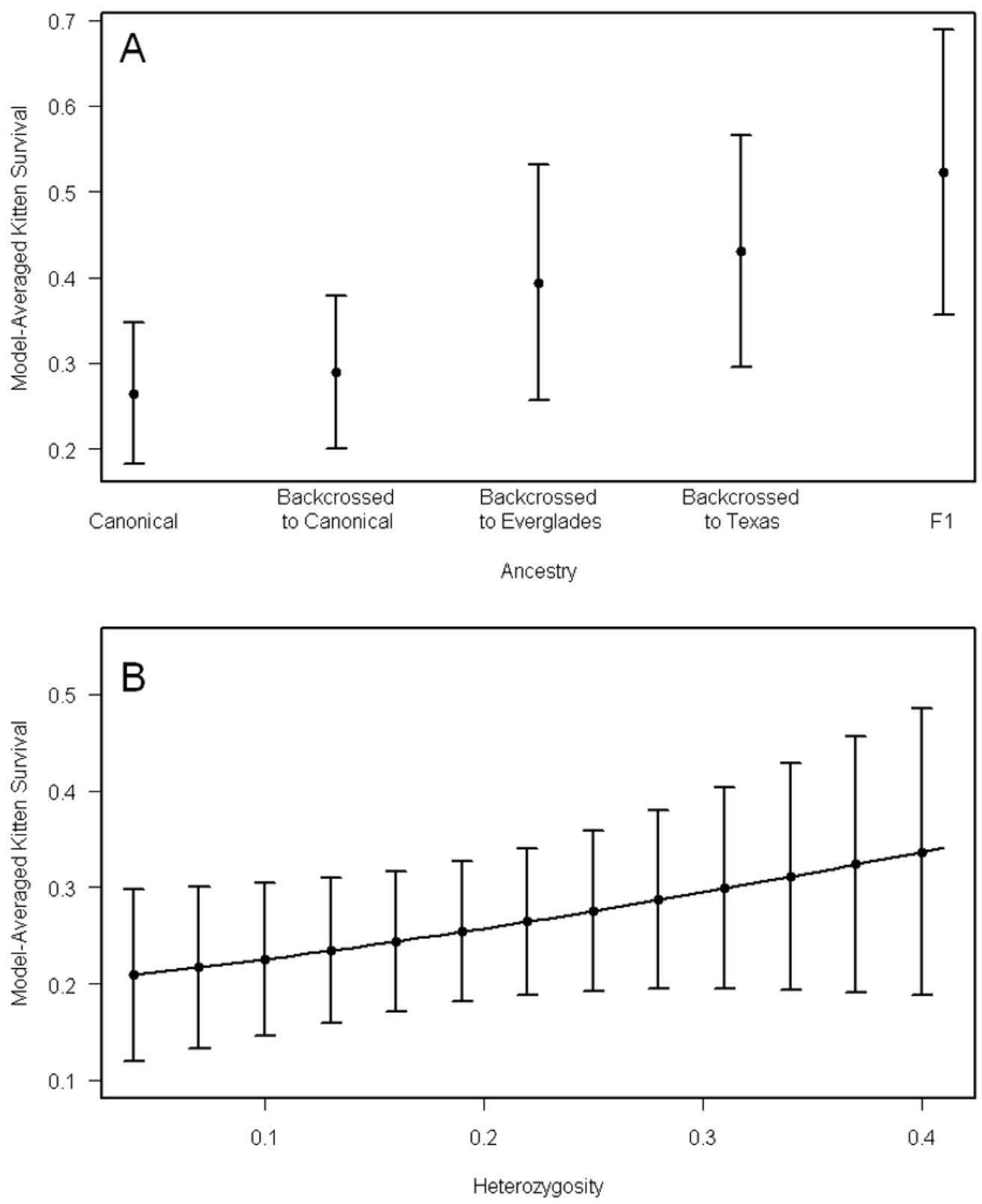

Figure 1.

The effect of genetic variables on model-averaged kitten survival estimates. A) Annual survival plotted against ancestry category. B) Annual survival plotted against heterozygosity. Error bars represent unconditional standard errors. 


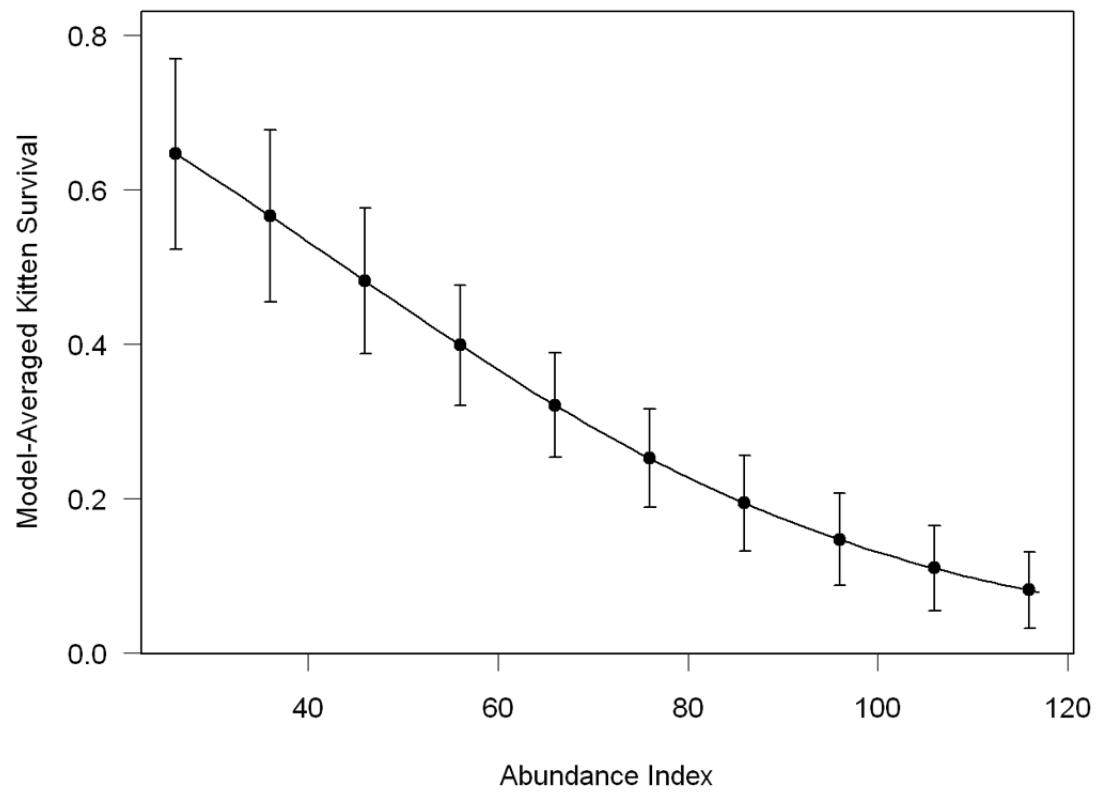

Figure 2.

The effect of a panther abundance index on model-averaged kitten survival estimates. Error bars represent unconditional standard errors. 


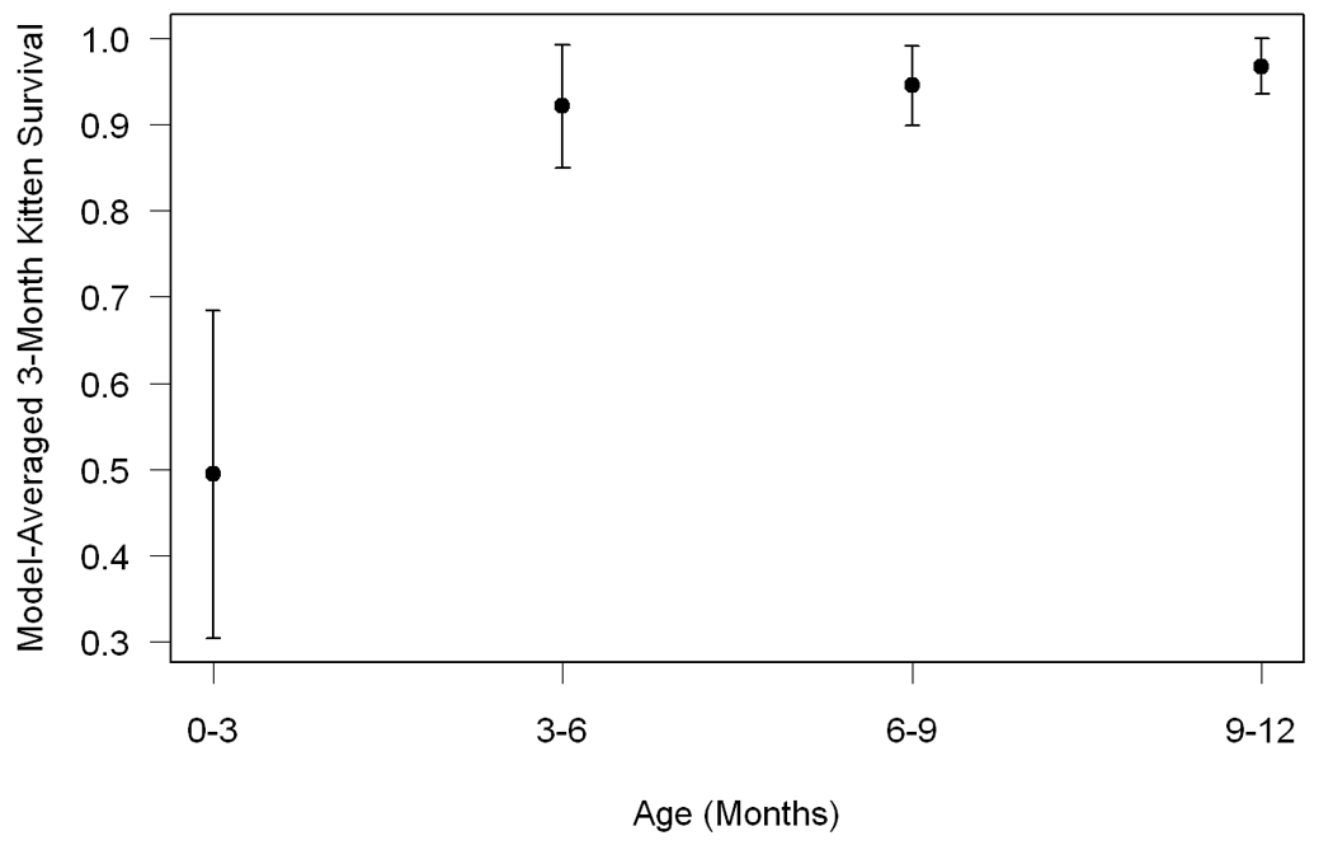

Figure 3.

Model-averaged kitten survival by 3 -month age interval within the first year. Error bars represent unconditional standard errors. 


\section{Table 1}

A) All a priori models that were used to test hypotheses regarding the effect of covariates on kitten survival probability $(S)$ and B) definitions of ancestry models. All models are based on the additive effects of covariates on survival of kittens (unless otherwise noted) from the base model(s) (base; see Table 2). s\&a indicates an effect on sub-adult and adult survival and $\mathrm{k}$ indicates an effect on kitten survival.

\begin{tabular}{|c|c|c|}
\hline \multicolumn{3}{|l|}{ A. All Models } \\
\hline Model & Description & \\
\hline 1. $S($ base $+\mathrm{k}: \mathrm{sex})$ & Additive sex effect & \\
\hline 2. $S($ base + k:LS) & Additive linear litter size effect & \\
\hline 3. $S$ (base $+\mathrm{k}$ :Ancestry $)^{*}$ & Additive ancestry effect (see below) on kitten survival & \\
\hline 4. $S(\text { base }+ \text { Ancestry })^{*}$ & Additive ancestry effect (see below) on survival of panthers of all ages & \\
\hline 5. $S(\text { base }+ \text { s\&a:F1Adv })^{*}$ & $\begin{array}{l}\text { Additive } F_{1} \text { ancestry effect (see below) on survival of sub-adult and adult } \\
\text { panthers only }\end{array}$ & \\
\hline 6. $S($ base + k:Ancestry + s\&a:F1Adv $){ }^{*}$ & $\begin{array}{l}\text { Separate additive ancestry effects (see below) on kitten survival and sub-adult } \\
\text { and adult survival ( } F_{1} \text { only) }\end{array}$ & \\
\hline 7. $S($ base $+\mathrm{k}: \mathrm{Het})$ & Additive linear heterozygosity effect on kitten survival & \\
\hline 8. $S($ base + Het $)$ & Additive linear heterozygosity effect on survival of panthers of all ages & \\
\hline 9. $S$ (base + s\&a:Het) & Additive linear heterozygosity effect on survival of sub-adults and adults only & \\
\hline 10. $S($ base $+\mathrm{k}: H e t+\mathrm{s} \& \mathrm{a}: H e t)$ & $\begin{array}{l}\text { Separate additive linear heterozygosity effects on survival of kittens and } \\
\text { survival of sub-adults and adults }\end{array}$ & \\
\hline 11. $S($ base $+\mathrm{k}:$ Abundance $)$ & Additive linear effect of abundance index & \\
\hline \multicolumn{3}{|l|}{ B. Ancestry Models } \\
\hline Term & Definition & Hypothesis \\
\hline IntAdv & $\begin{array}{l}2 \text { ancestry categories: 1) Canonical; 2) Backcrossed to Canonical, } \\
\text { Backcrossed to Everglades, Backcrossed to Texas, and } \mathrm{F}_{1} \text {. }\end{array}$ & $\begin{array}{l}\text { General introgression } \\
\text { advantage (or } \\
\text { disadvantage). }\end{array}$ \\
\hline AdmAdv & $\begin{array}{l}2 \text { ancestry categories: 1) Canonical and Backcrossed to Canonical; 2) } \\
\text { Backcrossed to Everglades, Backcrossed to Texas, and } \mathrm{F}_{1} \text {. }\end{array}$ & $\begin{array}{l}\text { General admixture } \\
\text { advantage (or } \\
\text { disadvantage), but with } \\
\text { Backcrossed to } \\
\text { Canonical reverting to } \\
\text { Canonical. }\end{array}$ \\
\hline 50TexAdv & $\begin{array}{l}2 \text { ancestry categories: 1) Canonical, Backcrossed to Canonical, and } \\
\text { Backcrossed to Everglades; 2) Backcrossed to Texas, and } \mathrm{F}_{1} \text {. }\end{array}$ & $\begin{array}{l}\text { Survival advantage (or } \\
\text { disadvantage) for those } \\
\geq 50 \% \text { Texas. }\end{array}$ \\
\hline CanDisF1Adv & $\begin{array}{l}3 \text { ancestry categories: 1) Canonical; 2) Backcrossed to Canonical, } \\
\text { Backcrossed to Everglades, and Backcrossed to Texas; and 3) } F_{1} \text {. }\end{array}$ & $\begin{array}{l}\text { Differences in survival } \\
\text { between pre- } \\
\text { introgression types, } \\
\text { backcrosses, and } F_{1} \text { 's. }\end{array}$ \\
\hline CanDis50TexAdv & $\begin{array}{l}3 \text { ancestry categories: 1) Canonical; 2) Backcrossed to Canonical and } \\
\text { Backcrossed to Everglades; 3) Backcrossed to Texas and } F_{1} \text {. }\end{array}$ & $\begin{array}{l}\text { Differences in survival } \\
\text { between pre- } \\
\text { introgression types, } \\
\geq 50 \% \text { Texas, and } \\
\text { intermediate types. }\end{array}$ \\
\hline F1Adv & $\begin{array}{l}2 \text { ancestry categories: 1) Canonical, Backcrossed to Canonical, Backcrossed } \\
\text { to Everglades, and Backcrossed to Texas; and 2) } F_{1} \text {. }\end{array}$ & $\begin{array}{l}\text { Survival advantage (or } \\
\text { disadvantage) for } \mathrm{F}_{1} \text { 's. }\end{array}$ \\
\hline
\end{tabular}




\section{Table 2}

Model comparison table to estimate annual kitten survival and select $t$ base model. For each model, we present the number of parameters $(\mathrm{K})$, the difference from the top model in Akaike's Information Criterion adjusted for overdispersion and small sample size $\left(\Delta \mathrm{QAIC}_{\mathrm{c}}\right)$, the model $\mathrm{QAIC}_{\mathrm{c}}$ weight, and the estimate of annual kitten survival with standard error. The base model selected is in bold (representing survival differing between kittens, females age 1 and 2, females 3 and older, males age 1-3, and males 4 and older; recapture the same for all uncollared panthers; and recovery differing between uncollared kittens and uncollared older panthers).

\begin{tabular}{lcccc}
\hline Model & $\mathbf{K}$ & $\boldsymbol{\Delta} \mathbf{Q A I C}_{\mathbf{c}}$ & Weight & Annual Kitten Survival Estimate (SE) \\
\hline $\mathbf{1 .} \mathrm{S}(\mathrm{k}, \mathbf{1} \leq \mathbf{f}<\mathbf{3}, \mathrm{f} \geq \mathbf{3}, \mathbf{1} \leq \mathrm{m}<\mathbf{4}, \mathbf{m} \geq \mathbf{4}) \mathbf{p}(.) \mathbf{r}(\mathbf{k}, \mathbf{s} \& \mathbf{a})$ & 8 & 0.00 & 0.155 & $0.343(0.077)$ \\
2. $\mathrm{S}(\mathrm{k}, 1 \leq \mathrm{f}<3, \mathrm{f} \geq 3,1 \leq \mathrm{m}<3, \mathrm{~m} \geq 3) \mathrm{p}(.) \mathrm{r}(\mathrm{k}, \mathrm{s} \& \mathrm{a})$ & 8 & 0.19 & 0.141 & $0.342(0.077)$ \\
3. $\mathrm{S}(\mathrm{k}, 1 \leq \mathrm{f}<2, \mathrm{f} \geq 2,1 \leq \mathrm{m}<4, \mathrm{~m} \geq 4) \mathrm{p}(.) \mathrm{r}(\mathrm{k}, \mathrm{s} \& \mathrm{a})$ & 8 & 0.24 & 0.138 & $0.345(0.078)$ \\
4. $\mathrm{S}(\mathrm{k}, 1 \leq \mathrm{f}<2, \mathrm{f} \geq 2,1 \leq \mathrm{m}<3, \mathrm{~m} \geq 3) \mathrm{p}(.) \mathrm{r}(\mathrm{k}, \mathrm{s} \& \mathrm{a})$ & 8 & 0.43 & 0.125 & $0.344(0.077)$ \\
5. $\mathrm{S}(\mathrm{k}, 1 \leq \mathrm{f}<3, \mathrm{f} \geq 3,1 \leq \mathrm{m}<4, \mathrm{~m} \geq 4) \mathrm{p}(.) \mathrm{r}()$. & 7 & 0.47 & 0.123 & $0.296(0.054)$ \\
6. $\mathrm{S}(\mathrm{k}, 1 \leq \mathrm{f}<3, \mathrm{f} \geq 3,1 \leq \mathrm{m}<3, \mathrm{~m} \geq 3) \mathrm{p}(.) \mathrm{r}()$. & 7 & 0.62 & 0.114 & $0.296(0.054)$ \\
7. $\mathrm{S}(\mathrm{k}, 1 \leq \mathrm{f}<2, \mathrm{f} \geq 2,1 \leq \mathrm{m}<4, \mathrm{~m} \geq 4) \mathrm{p}(.) \mathrm{r}()$. & 7 & 0.76 & 0.106 & $0.297(0.054)$ \\
8. $\mathrm{S}(\mathrm{k}, 1 \leq \mathrm{f}<2, \mathrm{f} \geq 2,1 \leq \mathrm{m}<3, \mathrm{~m} \geq 3) \mathrm{p}(.) \mathrm{r}()$. & 7 & 0.92 & 0.098 & $0.297(0.054)$ \\
9. $\mathrm{S}(\mathrm{k}+\mathrm{sex}, 1 \leq \mathrm{f}<3, \mathrm{f} \geq 3,1 \leq \mathrm{m}<4, \mathrm{~m} \geq 4) \mathrm{p}(.) \mathrm{r}(\mathrm{k}, \mathrm{s} \& \mathrm{a})$ & 9 & 2.02 & 0.267 & $0.349(0.084)^{a}$ \\
& & & & $0.335(0.089)^{b}$
\end{tabular}

${ }^{a}$ Female kitten survival.

${ }^{b}$ Male kitten ten survival. 


\section{Table 3}

Model selection table for A) ancestry effects on kitten and older survival, B) heterozygosity effects on kitten and older survival, and C) abundance index effects on kitten survival. These analyses were performed on subsets of the data (excluding panthers before 1995 for all analyses and panthers of unknown ancestry for A, and panthers before their heterozygosity was successfully sampled for B). For each model, we present the number of parameters $(\mathrm{K})$, the difference from the top model in Akaike's Information Criterion adjusted for overdispersion and small sample size $(\triangle \mathrm{QAIC})$, and the model $\mathrm{QAIC}_{\mathrm{c}}$ weight. See Table 1 for descriptions of the covariate models and Table 2 for the base model. All models estimate constant recapture rates and recovery rates that differ between kittens and older panthers $(p() r.(\mathrm{k}, \mathrm{s} \& \mathrm{a}))$.

\begin{tabular}{|c|c|c|c|}
\hline \multicolumn{4}{|l|}{ A. Ancestry models } \\
\hline Survival Model & $\mathbf{K}$ & $\Delta \mathrm{QAIC}_{\mathrm{c}}$ & Weight \\
\hline 1. base + k:AdmAdv + s\&a:F1Adv & 10 & 0.00 & 0.242 \\
\hline 2. base + AdmAdv & 9 & 1.34 & 0.124 \\
\hline 3. base + F1Adv & 9 & 1.44 & 0.118 \\
\hline 4. base + CanDisF1Adv & 10 & 1.99 & 0.090 \\
\hline 5. base + k:50TexAdv + s\&a:F1Adv & 10 & 2.38 & 0.074 \\
\hline 6. base + k:AdmAdv & 9 & 3.27 & 0.047 \\
\hline 7. base + s\&a:F1Adv & 9 & 3.35 & 0.045 \\
\hline 8. base $+50 \mathrm{TexAdv}$ & 9 & 3.43 & 0.044 \\
\hline 9. base + k:F1Adv + s\&a:F1Adv & 10 & 3.46 & 0.043 \\
\hline 10. base + k:IntAdv + s\&a:F1Adv & 10 & 3.49 & 0.042 \\
\hline 11. base + k:CanDis50TexAdv + s\&a:F1Adv & 11 & 3.98 & 0.033 \\
\hline 12. base + k:CanDisF1Adv + s\&a:F1Adv & 11 & 4.22 & 0.029 \\
\hline 13. base + CanDis50TexAdv & 10 & 4.92 & 0.021 \\
\hline 14. base + IntAdv & 9 & 5.56 & 0.015 \\
\hline 15. base + k:50TexAdv & 9 & 5.80 & 0.013 \\
\hline 16. base $+\mathrm{k}:$ IntAdv & 9 & 7.34 & 0.006 \\
\hline 17. base $+\mathrm{k}:$ CanDis50TexAdv & 10 & 7.36 & 0.006 \\
\hline 18. base & 8 & 7.43 & 0.006 \\
\hline \multicolumn{4}{|l|}{ B. Heterozygosity models } \\
\hline Survival Model & $\mathrm{K}$ & $\triangle \mathrm{QAICc}$ & Weight \\
\hline 1. base + Het & 9 & 0.00 & 0.325 \\
\hline 2. base $+s \& a: H e t$ & 9 & 0.75 & 0.223 \\
\hline 3. base & 8 & 0.91 & 0.206 \\
\hline 4. base $+\mathrm{k}:$ Het & 9 & 1.88 & 0.127 \\
\hline 5. base $+\mathrm{k}:$ Het $+\mathrm{s} \& \mathrm{a}: \mathrm{Het}$ & 10 & 2.00 & 0.119 \\
\hline \multicolumn{4}{|l|}{ C. Abundance index models } \\
\hline Survival Model & $\mathrm{K}$ & $\triangle \mathrm{QAICc}$ & Weight \\
\hline 1. base $+\mathrm{k}$ :Abundance & 9 & 0.00 & 0.988 \\
\hline 2. base & 8 & 8.79 & 0.012 \\
\hline
\end{tabular}

